\title{
ФУНДАМЕНТАЛЬНАЯ ИММУНОБИОЛОГИЯ ПРОВОСПАЛИТЕЛЬНЫХ ЦИТОКИНОВ И MIF
}

\section{Суслов А.П., Коноплева М.В., Третьяков О.Ю.}

\author{
ГУ НИИЭМ им.Н.Ф.Гамалеи РАМН, Москва, Россия
}

Резюме. Сравнение цитокинов и MIF по основным общебиологическим свойствам показывает наличие, как сходства, так и существенных различий. Особенностями MIF являются уникальность его структуры, повсеместная распространенность в органах и тканях организма, исключительно широкое разнообразие функций (провоспалительный цитокин, фермент, гормон), способность индуцироваться глюкокортикоидами и оказывать контррегулирующее действие на их иммуносупрессивные эффекты. MIF находится в преформированном состоянии в лимфоцитах, макрофагах и клетках эндотелия. Он выделяется этими клетками и функционирует как фактор мобилизации защитной системы уже в первые минуты чужеродного воздействия. MIF проявляет свойства суперлиганда, связываясь со множеством биологически важных молекул, Этот фактор осуществляет функции, важные для активации клетки, ее размножения и гибели, используя разнообразные внутриклеточные сигнальные пути. В эволюции гомологи MIF обнаруживают уже у растений и бактерий, то есть до появления адоптивной и врожденной иммунной системы. В онтогенезе MIF появляется уже на стадии первых клеточных делений. Широта функций MIF многообразие его лигандных связей, разнообразие путей реализации функций, повсеместное распространения в организме, раннее появление в онтогенезе и филогенезе, а также в ходе защитной реакции клетки и организма в целом - все эти факторы вместе взятые позволяют позиционировать MIF как особый тип цитокина - эоцитокин (от греческого эо - ранний). Предполагается, что MIF может функционировать как ключевой фактор «естественной устойчивости» клетки и организма.

\section{История вопроса}

MIF (macrophage migration inhibition factor) был открыт в 1965 г. среди первых цитокинов одновременно и независимо в лабораториях B. Bloom [16] и J. David [31]. MIF довольно интенсивно исследовался в течение 15 лет. Однако, когда в начале 80-х годов в работах с рекомбинантными цитокинами основное свойство MIF - подавлять миграцию макрофагов in vitro - было продемонстрировано и для других цитокинов (IFN- $\gamma$, TNF- $\alpha$, IL-1), исследования по MIF были практически свернуты. Вторичное открытие MIF состоялось в 1989 г., когда J. David и соавт. впервые установили первичную аминокислотную последовательность MIF [125]. В настоящее время исследования по MIF идут очень интенсивно и по разным направлениям, что обусловлено многообразием его функций, свойств и значением как ключевого провоспалительного и иммунорегуляторного фактора, а также фермента [60, 61, 91], гормона [6] и регулятора гомеостаза глюкозы [121]. Показано, что MIF является важным фактором патогенеза ряда заболеваний аутоиммунной природы (ревматоидный артрит, гломерулонефрит, псориаз, рассеянный склероз и др.), онкогенеза и сепсиса [32, 74]. Поэтому в мире идет разработка фармакологических средств, направленных на нейтрализацию MIF. Фирма Baxter запатентовала полученные методом фагового дисплея антитела против MIF для использования в качестве потенциального терепевтического средства при ряде заболеваний [126].

Учитывая, что исследования MIF несколько затормозились, по сравнению с исследованиями по другим цитокинам, и, принимая во внимание большой объем литературных данных, полученный уже в «новой эре» MIF-ологии, представляется важным по-новому спозиционировать MIF в отношении семейства цитокинов.

\author{
Адрес для переписки: \\ Суслов Анатолий Петрович \\ 123098, Москва, ул.Гамалеи, д.18, \\ ГУ НИИЭМ им.Н.Ф.Гамалеи РАМН, лаборатория \\ эффекторов и медиаторов воспаления. \\ Тел.: (495)193-61-31, факс (495) 193-43-50. \\ E-mail: Anatoly.suslov@nearmedic.ru
}

\section{Общая характеристика функциональной активности цитокинов и MIF}

Цитокины - это растворимые белки или пептиды, синтез и продукция которых происходит преимущественно в ответ на стресс-воздействие. Концентрация в локальной межклеточной жидко- 
сти или в циркуляции, в которой цитокины осуществляют свою функцию очень низка (пг/мл), Цитокины действуют неферментативно, посредством связывания со специфическими рецептора- ми, регулируют функции клеток защитной системы организма, включая их циркуляцию, хемотаксис, активацию, размножение и гибель, а также гемопоэз.

ТабЛ. 1. СРАВНЕНИЕ ОСНОВНЫХ БИОЛОГИЧЕСКИХ СВОЙСТВ ЦИТОКИНОВ И МІF

\begin{tabular}{l|l}
\hline Биологические свойства, общие для MIF и цитокинов & \multicolumn{1}{c}{ Особенности MIF } \\
\hline $\begin{array}{l}\text { Регуляторные белки и пептиды с мол. м. от } 5 \text { до } 50 \\
\text { кДа, не являющие гормонами }\end{array}$ & Может продуцироваться и действовать как гормон \\
\hline $\begin{array}{l}\text { Синтезируются практически всеми клетками } \\
\text { организма, преимущественно в ответ на стресс }\end{array}$ & Нет отличий \\
\hline $\begin{array}{l}\text { Обладают плейотропностью и взаимозаменяемостью } \\
\text { действия }\end{array}$ & Нет отличий \\
\hline Не имеют антигенной специфичности & Имеются отдельные антиген-специфичные формы MIF \\
\hline $\begin{array}{l}\text { Активация генов и синтез цитокинов индуцируется } \\
\text { в ответ на сигнал }\end{array}$ & $\begin{array}{l}\text { МІF может присутствовать в префрормированном } \\
\text { состоянии }\end{array}$ \\
\hline $\begin{array}{l}\text { Проводят сигнал посредством специфических } \\
\text { клеточных рецепторов }\end{array}$ & $\begin{array}{l}\text { Может встраиваться в сигнальные пути после } \\
\text { эндоцитоза без рецепторов }\end{array}$ \\
\hline Образуют цитокиновую сеть & Нет отличий \\
\hline Действуют дистантно (местно или системно) & Нет отличий \\
\hline
\end{tabular}

\section{Табл. 2. ФИЗИОЛОГИЧЕСКАЯ АКТИВНОСТЬ MIF}

\begin{tabular}{|c|c|}
\hline Физиологическая активность MIF & Ссылки \\
\hline 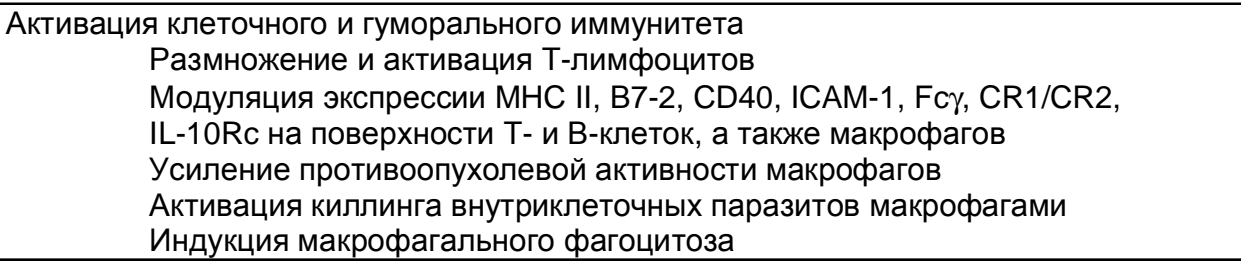 & $\begin{array}{l}{[1,9]} \\
{[107]} \\
{[93]} \\
{[52,101]} \\
{[85]}\end{array}$ \\
\hline $\begin{array}{l}\text { Супрессивное действие } \\
\text { Подавление активности NK-клеток } \\
\text { Подавление колониеобразования: эритроидного и мультипотентного } \\
\text { гранулоцитарно-макрофрагального }\end{array}$ & $\begin{array}{c}{[7]} \\
{[21,22]}\end{array}$ \\
\hline 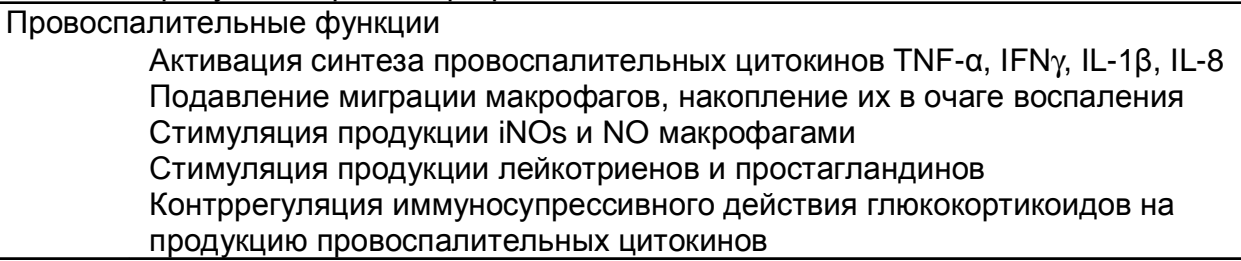 & $\begin{array}{l}{[45,65,72,94,115]} \\
{[16,31]} \\
{[29,101]} \\
{[32]} \\
{[21,30,34]}\end{array}$ \\
\hline $\begin{array}{l}\text { Регуляция хемотаксиса } \\
\text { Подавление миграции моноцитов, вызванной хемокинами } \\
\text { Усиление рекрутации моноцитов и лейкоцитов из циркуляции путем их } \\
\text { остановки и прикрепления к эндотелию сосудов } \\
\text { Увеличение выхода лейкоцитов из сосудов при гормональном стрессе } \\
\text { Усиление миграции опухолевых клеток } \\
\text { Усиление экспрессии ICAM-1 и VCAM-1 }\end{array}$ & $\begin{array}{c}{[76]} \\
{[25,65]} \\
{[38]} \\
{[94]} \\
{[65,73]}\end{array}$ \\
\hline $\begin{array}{l}\text { Регуляция клеточного деления и регенерации тканей } \\
\text { Стимуляция или угнетение клеточной пролиферации в зависимости от } \\
\text { контекста и типа клеток } \\
\text { Стимуляция продукции TGF-ß1 } \\
\text { Стимуляция неоангиогенеза } \\
\text { Стимуляция продукции VEGF } \\
\text { Индукция продукции металлопротеиназ MMP9 и MMP13 } \\
\end{array}$ & $\begin{array}{c}{[22,32]} \\
{[71]} \\
{[10,26]} \\
{[94]} \\
{[72,84]}\end{array}$ \\
\hline $\begin{array}{l}\text { Регуляция апоптоза } \\
\text { Угнетение экспрессии регуляторов клеточного цикла р21 и циклина G } \\
\text { Контррегулятор экспрессии р53 }\end{array}$ & $\begin{array}{c}{[48]} \\
{[28,83]}\end{array}$ \\
\hline $\begin{array}{l}\text { Регуляция метаболизма клеток } \\
\text { Стимулирует обмен глюкозы и регулирует секрецию инсулина } \\
\text { Увеличивает синтез фруктозо-2,6-дифосфата (позитивного } \\
\text { аллостерического регулятора гликолиза) } \\
\text { Увеличивает число свободных тиоловых групп на жгутиках } \\
\text { сперматозоидов }\end{array}$ & $\begin{array}{r}{[122]} \\
{[13]} \\
{[36]}\end{array}$ \\
\hline
\end{tabular}


Основные и наиболее известные функции MIF способность подавлять миграцию макрофагов, активировать макрофаги in vitro, организовывать воспалительный очаг с повышенной концентрацией макрофагов (типа реакции ГЗТ в тканях) in vivo, явились причиной того, что MIF исторически относят к провоспалительным цитокинам. Действительно, если сравнить фундаментальные биологические свойства цитокинов и MIF (табл. 1), то MIF, несомненно, может быть отнесен к цитокинам. В то же время, уже из этой таблицы следует, что MIF имеет и другие, дополнительные свойства. Так, MIF может иметь антиген-специфичные формы, присутствовать в клетках в преформированном состоянии, встраиваться во внутриклеточные сигнальные пути после эндоцитоза без обязательного для цитокинов взаимодействия со специфическими рецепторами. Последнее свойство указывает на то, что MIF, в отличие от классических цитокинов, способен не только выполнять роль сигнальной молекулы, но и быть непосредственным молекулярным участником внутриклеточного этапа прохождения сигнальных процессов. Кроме того, оба идентифицированные в настоящее время неспецифические «рецепторы» для MIF (CD74 и CD44) [69] совершенно не похожи на рецепторы для других цитокинов, ни по структуре, ни по фунциональным свойствам, и должны рассматриваться особо.

MIF обладает многими общебиологическими и иммунологическими функциями, выполняемыми разными цитокинами. Однако, в отличие от цитокинов, функции которых более или менее специализированы по отдельным семействам [131], MIF характеризуется выраженной полифункциональностью (см. табл. 2). Кроме того, MIF обладает рядом особых по сравнению с провоспалительными цитокинами биологических функций. Так, например, он осуществляет локальное накопление макрофагов in vivo и организует реакцию ГЗТ, стимулирует опухолевый неоангиогенез, рост и миграцию опухолевых клеток $[16,31,99]$. Для других цитокинов такой активности не установлено, хотя показано, что некоторые из них (IFN- $\gamma$, TNF- $\alpha$ или IL-1) могут тормозить миграцию макрофагов in vitro $[19,21,22]$. Кроме того, MIF единственный известный в настоящее время контррегулятор иммуносупрессивного действия глюкокортикоидов на продукцию цитокинов [19].

\section{Структура}

Классификация цитокинов по строению учитывает не только аминокислотную последовательность, но, прежде всего, особенности их третичной организации, более полно отражающие эволюционное происхождение молекул [132].

Для цитокинов типа I характерно наличие $4 \alpha$ спиралей, сложенных пучком. В зависимости от дли- ны этих спиралей цитокины I типа подразделяются на короткоцепочечные (IL-2, -3, -4, -5, -7, -9, -13, -15, TLSP, SCF, M-CSF, GM-CSF) и длинноцепочечные (IL-6, -10, -11, -12, G-CSF, EPO, TPO, пролактин, лептин). У короткоцепочечных цитокинов $\alpha$-спирали имеют обычно по 15 а.к.о., в то время как для длинноцепочечных характерна длина в 25 а.к.о., $\alpha$-спирали складываются в виде двух петель - АВ и $\mathrm{CD}$. У короткоцепочечных цитокинов петля $\mathrm{AB}$ расположена над $\mathrm{CD}$, а у длинноцепочечных - под $\mathrm{CD}$.

Цитокины типа II (IFN- $\alpha / \beta$, IFN- $\gamma$, IL-10, -20, -22) имеют иную структуру. IL-10 -гомодимер, где каждый из мономеров содержит домен, образованный шестью $\alpha$-спиральными участками. Мономеры ориентированы под углом $90^{\circ}$ по отношению друг к другу [50, 70]. Домены IL-10 проявляют структурное сходство с интерферонами, существующими в форме мономера (IFN- $\alpha$, IFN- $\beta$ и IFN- $\tau$ ) или димера (IFN$\gamma)$. IFN- $\gamma$, существующий в растворе в виде димера, включает преимущественно $\alpha$-спирали $(62 \%)$ и совсем не содержит $\beta$-листов. Каждая субъединица в димере состоит из шести $\alpha$-спиралей [35]. IFN- $\beta$ имеет дополнительную $\alpha$-спираль вместо петли $\mathrm{CD}$, по сравнению с цитокинами типа I. Сопоставление структуры IFN- $\beta$ с другими $\alpha$-спиральными цитокинами (например, свиной гормон роста, IL-2 и IFN- $\gamma$ ), выявляет наличие топологического сходства в фолдинге цепей. Функционально важные сегменты полипептидной цепи образуют пространственные кластеры, связывающиеся с рецепторами [102].

MIF имеет ряд особенностей в структуре, ставящих его особняком среди цитокинов. Вторичная структура мономера MIF состоит из двух антипараллельных $\alpha$-спиралей и шести $\beta$-листов, четыре из которых образуют подложку, над которой поднимаются $\alpha$-спирали. Эта структура очень похожа на пептидсвязывающий домен МНС класса II. Третичная структура MIF достаточно уникальна. Он представляет собой гомотример в виде бочонка с открытыми концами. По центру бочонка вдоль молекулярной оси расположен канал диаметром 4-15 А, образованный преимущественно гидрофильными, положительно заряженными атомами. По третичной структуре MIF подобен лишь D-дофахром-таутомеразе (из млекопитающих и бактерий), а также бактериальным 4-оксалокротонат-изомеразе и 5-карбокиметил-2-гидроксимуконат-изомеразе. Несмотря на сходство с бактериальными ферментами по топологии, MIF имеет мало общего с ними по аминокислотной последовательности. В то же время он имеет значительную гомологию по первичной и третичной структуре с Dдофахром-таутомеразой млекопитающих [109]. Отличительной особенностью MIF как представителя семейства таутомераз является $\mathrm{N}$-концевой пролин. Уникальность структуры MIF среди цитокинов дало основание предположить, что MIF участвует в лиганд-рецепторных взаимосвязях нового типа [19]. 


\section{Гомология и эволюция}

Развитие системы цитокинов происходило параллельно с эволюцией адаптивного иммунитета [27]. Поскольку адаптивный иммунитет появился на уровне челюстных позвоночных, то логично предположить, что и цитокины, контролирующие этот вид иммунитета, появились в тот же временной период. Однако, достижения в области клонирования цитокинов у низших классов позвоночных в настоящее время невелики. Например, клонирование интерлейкинов проведено только у птиц. Рецепторы для этих интерлейкинов клонированы у рыб, что предполагает наличие соответствующих цитокинов. Провоспалительные интерлейкины клонированы у птиц, рыб и амфибий, но не у рептилий [53]. Хемокины идентифицированы у птиц, амфибий и рыб, включая миноги [64]. У рыб обнаружен TNF, но показано, что он существует в единственной форме, в отличие от TNF млекопитащих, представленного в виде TNF- $\alpha$ и TNF- $\beta$. Тем не менее, TNF рыб по структуре белка и локализации его гена похож на TNF- $\alpha$ млекопитающих [44]. Филогенетический анализ членов семейства IL-1, включающий более 80 первичных последовательностей разнообразных рыб, амфибий, птиц и млекопитающих, позволил обнаружить, что только несколько членов семейства IL-1 млекопитающих однозначно ортологичны соответствующим аналогам у рыб. Это доказывает недавнее происхождение некоторых членов семейства IL-1 у млекопитающих. Интересно, что в геноме рыбы фугу выявляются древние предшественники IL-18 и их предполагаемый рецептор.

Исследования о наличии цитокинов у беспозвоночных в целом мало развиты. У морских звезд, например, с помощью поли- и моноклональных антител был идентифицирован IL-6-подобный фактор. У моллюсков было продемонстрировано наличие цитокиноподобных факторов, оказывающих влияние на функции иммунной системы, такие как подвижность клеток, хемотаксис, фагоцитоз и цитотоксичность [86]. В частности, IL-1 $\alpha$ и TNF- $\alpha$ оказывают воздействие на клеточную миграцию у беспозвоночных в зависимости от их вида, а IL-8, PDGFAB и TGF- $\beta 1$ - в зависимости от дозы. Показано, что IL-8, PDGF-AB и TGF- $\beta 1$ провоцируют изменения в иммуноцитах моллюсков, запуская сигнальную трансдукцию, опосредованную фосфатидилинозитолом и сAMP. PDGF-AB и TGF- $\beta 1$ частично ингибируют клеточный апоптоз в клеточной линии насекомых, причем эффект выживания опосредован активацией фосфатидилинозитол-3-киназы, РКА и PКС. Более того, IL- $1 \alpha$, IL-2 и TNF- $\alpha$ способны индуцировать экспрессию NO-синтетазы у моллюсков. Показано, что цитокины также вовлечены в ответ на стресс у беспозвоночных. При этом механизм их воздействия очень похож на механизм в клетках позвоночных. Некоторые исследования демонстрируют существование на мембранах клеток моллюсков существование рецепторов, способных связывать как цитокин (IL-2), так и гормон (CRH). Отсутствие выраженной избирательности рецепторов и множественность функций цитокинов у беспозвоночных, в сочетании с существенными различиями между генами цитокинов у беспозвоночных и позвоночных, указывают на особый путь эволюции цитокинов [86].

В отличие от цитокинов, MIF идентифицирован практически у всех основных видов животных, представленных на эволюционном древе. Гомологи MIF имеются у бактерий, растений, червей (см. табл. 3 и 4). Таким образом, аналоги MIF появились, по-видимому, задолго до формирования не только системы адаптивного иммунитета, но и до формирования системы врожденного иммунитета. Достаточно высокая степень гомологии MIF позвоночных в сравнении с MIF нематод (около 27\% с MIF-2 B. malayi) свидетельствует о том, что этот фактор был законсервирован в течение, по крайней мере, 1 миллиарда лет эволюции.

Каковы функции отдаленных предшественников MIF, которые они могли бы реализовать у низших животных и растений, остается неизвестным. Существующее предположение о том, что MIF был дальним предком глютатион-S-трансферазы, позволяет связать иммунную систему с детоксифицирующей [14]. Предполагается также, что MIF мог эволюционировать от общего предка для него и дофахромтаутомеразы [37], однако это не дает возможности приблизиться к пониманию роли предковых форм MIF, поскольку функция таутомераз пока недостаточно ясна ни для низших животных, ни для млекопитающих. Можно предположить, что MIF мог быть встроен в систему стресс-протеинов, состоящую из наиболее древних и консервативных белков, обеспечивающих выживание клетки как таковой. В настоящее время идентифицировано всего около 370 самых консервативных белков, основные функции которых сводятся к регуляции редокс-потенциала клетки и препятствию агрегации макромолекул, то есть двум наиболее жизненно важным функциям, позволяющим клеткам выживать при стресс-воздействиях любой природы [62]. MIF может быть включен в когорту этих стресс-протеинов не только потому, что он высококонсервативен, но и потому, что обладает множеством биологических функций, включая ферментативные активности, в том числе, может участвовать в редокс-регуляции [41].

Многообразие гомологов MIF, включая белки с очень высокой степенью гомологии - 87-99\% (см. табл. 3, 4), а также наличие большого количества псевдогенов MIF и/или близкородственных MIF генов позволяет выдвинуть предположение о существовании семейства MIF-белков [97]. 


\section{Продукция}

MIF - единственный из цитокинов, который обнаруживается в клетках разных органов и тканей в преформированном состоянии. Основным источником MIF являются Т-лимфоциты, моноциты, макрофаги, клетки эндотелия, гепатоциты и нейроны. Преформированный MIF был обнаружен во всех клетках иммунной системы, в клетках головного мозга (в нейронах коры, гипоталамуса, мозжечка, гиппокампа, в глиальных клетках, астроцитах и клетках эпендимы), в легких (в легочных макрофагах и эпителиальных клетках), в эндокринной системе (в клетках аденогипофиза, надпочечниках и $\beta$-клетках поджелудочной железы) и в пищеварительном тракте (в клетках эпителия пищевода, желудка и толстого кишечника, в окончаниях нейронов). Его также детектировали в печени (гепатоцитах, купферовских клетках, клетках эндотелия) и почках (в эпителиальных, эндотелиальных и мезангиальных клетках), в коже (в кератиноцитах, эндотелиальных клетках и фибробластах, клетках сальных желез, волосяных фолликулов). В костях и суставах (в остеобластах, фибробластах и синовиоци- тах), в репродуктивных органах (в клетках Лейдига, ооцитах, эпителиальных и фолликулярных клетках), в сердце, молочной железе, глазах и т.д. также были обнаружены везикулы, содержащие MIF [22, 32, 74]. Кроме того, MIF интенсивно продуцируется разнообразными опухолевыми клетками [28].

Установлено, что при беременности MIF экспрессируется клетками эндометрия [3], в больших количествах обнаруживается в трофобластах, клетках зародыша (зиготе, 3-клеточном эмбрионе, 8-клеточном эмбрионе и бластоцистах) [111] и в ворсинках хориона [8].

MIF продуцируется конститутивно в ряде клеток организма, прежде всего в лимфоцитах, макрофагах, а также в клетках эндотелия. Показано, что базовый уровень преформированного MIF в циркулирующих Т-лимфоцитах здоровых доноров выше более, чем в два раза, чем в макрофагах или В-лимфоцитах [67]. В то же время, в других тканях MIF в преформированном состоянии накапливается главным образом в макрофагах, а также в эндотелии практически всех слизистых оболочек [22, 32]. После стимуляции этих клеток каким-либо раздражи-

ТабЛ.3. ГОМОЛОГИЯ ПЕРВИЧНОЙ ПОСЛЕДОВАТЕЛЬНОСТИ МІF И ДРУГИХ БЕЛКОВ

\begin{tabular}{l|c|c}
\hline \multicolumn{1}{c|}{ Гомологи MIF } & Степень гомологии (в \%) & Ссылки \\
\hline $\begin{array}{l}\text { МІF различных видов животных, червей и } \\
\text { растений }\end{array}$ & $22-98$ & {$[113]$} \\
\hline D-дофрахром- таутомераза & 27 & {$[63,96]$} \\
\hline Глютатион-S-трансфераза (GST) & 99 & {$[80,124]$} \\
\hline $\begin{array}{l}\text { Гликозилирование- ингибирующий фактор } \\
\text { (GIF) }\end{array}$ & $25-35$ (для первых 30 а.к.о.) & {$[66]$} \\
\hline $\begin{array}{l}\text { Продукт генов замедленного } \\
\text { раннего ответа }\end{array}$ & 88 & {$[42]$} \\
\hline р12 из головного мозга быка & 88 & {$[127]$} \\
\hline Белок 10k хрусталика глаза эмбрионов кур & 99 & {$[97]$} \\
\hline $\begin{array}{l}\text { Глютатион-связывающий белок 13к из } \\
\text { печени крыс }\end{array}$ & $87-99$ & \\
\hline
\end{tabular}

Табл.4. БЕЛКИ СЕМЕЙСТВА МІF

\begin{tabular}{l|l|c}
\hline & Bиды животных & Ссылки \\
\hline \multirow{4}{*}{ Позвоночные } & Homo sapiens & \\
& Mus musculus & \\
& Rattus norvegicus & {$[108,113]$} \\
& Wuchereria bancrofti & \\
& Bos taurus & \\
& Gallus gallus & [32] \\
\hline Цианобактерии & Penopus laevis & \\
& Synechocococcus marinus sp. & [77, 113] \\
Нематоды & Caenorhabditis elegans & \\
& Brugia malayi & {$[49]$} \\
\hline Насекомые & Wuchereria bancrofti & {$[112]$} \\
\hline Растения & Trichuris spp. & {$[39]$} \\
\hline Простейшие & Trichinella sp. & Amblyomma americanum \\
\hline
\end{tabular}


телем - липополисахаридом, глюкокортикоидами, грампозитивными эндотоксинами, провоспалительными цитокинами (TNF- $\alpha$ и IFN- $\gamma$ ) - макрофаги выбрасывают преформированный MIF в межклеточное пространство и в циркуляцию [32]. Вслед за выбросом преформированного MIF в клетках начинается синтез этого фактора de nоvо в увеличенных количествах. Так, стимуляция клеток периферической крови человека форболмиристатацетатом (РМА) вместе с иономицином приводит к удвоению содержания MIF в $\mathrm{CD}^{+} \mathrm{T}$-лимфоцитах, а также к утроению содержания этого цитокина в макрофагах CD14 $4^{+}$[67].

У MIF отсутствует классическая N-концевая лидерная последовательность и его выделение происходит нестандартным путем. Среди цитокинов подобный тип секреции имеют только IL-1 и фактор роста фибробластов (FGF) [32]. Сильное ингибирование секреции MIF глибуридом и пробеницидом, но не другими ингибиторами неклассического экспорта белков, привело исследователей к заключению, что секреция MIF опосредована транспортной системой АВСА1 [40].

В отличие от цитокинов, концентрация которых в сыворотке крови даже при стрессе составляет всего несколько пг/мл, MIF в норме циркулирует постоянно в относительно высокой концентрации (у человека - 2-5 нг/мл). При этом концентрация его в сыворотке колеблется с циркадным ритмом, обладая выраженным максимумом ранним утром, который совпадает с максимумом для глюкокортикоидов [91]. Таким образом, постоянное присутствие MIF является важным физиологическим фактором нейроиммуноэндокринной регуляции организма.

На самых ранних этапах развития физиологического стресса или инфекции (уже с первых минут), преформированный MIF выделяется системно, циркулирует уже в повышенных количествах (у человека - до 50 нг/мл и выше), обеспечивает мобилизующее действие как провоспалительный цитокин [32] и в то же время, становится потенциально опасным для организма патогномоничным фактором.

Таким образом, MIF вовлечен в механизм самой ранней стресс-мобилизации организма, где он обеспечивает выход моноцитов и макрофагов из циркуляции, их накопление в очаге воспаления, активацию макрофагов и Т-лимфоцитов и запуск продукции других провоспалительных цитокинов.

\section{Рецепторы}

Цитокины являются сигнальными молекулами и их функции реализуются опосредованно, путем взаимодействия со специфическими рецепторами. Строение цитокиновых рецепторов в настоящее время достаточно хорошо изучено. На основании гомологии первичной структуры и особенностей органи- зации внеклеточных доменов они подразделяются на следующие классы: I (гемопоэтиновые), II (peцепторы интерферонов), III (рецепторы TNF), IV (рецепторы IL-1), суперсемейство иммуноглобулиновых рецепторов, рецепторы хемокинов и других цитокинов (IL-2, -15, TGF $\beta$ ). Подробно цитокиновые рецепторы обсуждены в обзоре [89].

По-видимому, MIF существенно отличается от цитокинов в отношении структуры своих рецепторов и даже самой необходимости их существования. Специализированные рецепторы для MIF пока не обнаружены, несмотря на то, что имеется немало данных об активирующем воздействии внеклеточного MIF на клетки. Более того, специальные исследования с использованием MIF, меченного флюоресцеином или $\mathrm{I}^{135}$, показали, что у большого количества клеток-мишеней существует неопосредованный рецепторами механизм проникновения MIF в клетку посредством эндоцитоза [57]. Цитокиновые рецепторы разных типов не обладали свойствами рецепторов для MIF. B то же время, несколько MIFсвязывающих белков были идентифицированы не на поверхности, а внутри клетки (например, JAB-1, PAG) (см. табл. 7).

На поверхности клеток же выявлен к настоящему моменту лишь один кандидат на роль рецептора для MIF. Этот MIF-связывающий белок не похож ни на один из рецепторов цитокинов, и вообще на рецептор - а именно, это инвариантная цепь МНС II (CD74) [69]. Однако взаимодействие MIF c CD74 приводит к активации МАРК-сигнального пути (см. табл. 6). С другой стороны, продемонстрировано, что для реализации ряда функций MIF необходимо образование комплекса CD74 с CD44 [69]. Не исключено, что MIF может напрямую связываться с CD44, внутриклеточная часть которого ассоциирована с актином. В этом случае образование комплекca MIF c CD44 с последующей реорганизацией цитоскелета - одно из возможных объяснений механизмов подавления миграции макрофагов, вызываемого MIF.

В целом же, следует подчеркнуть, что отличие MIF от обычных цитокинов состоит не столько в структуре его «рецепторов», но скорее в том, что он обладает способностью выполнять ряд функций после его эндоцитоза, и вовсе не опосредованного рецепторами [58].

\section{Гормональная регуляция}

Согласованное функционирование гипоталамогипофизарно-адреналового комплекса (ГГАК) и симпатической нервной системы (CHC) критично для выживания и поддержания здоровья организма. Регуляция ГГАК и СНС в ходе развития сложилась пластичной, комплексной и многоуровневой [17]. С одной стороны, регуляция активности цито- 
кинов находится под плотным контролем гормонов на уровне процессинга и/или экспрессии рецепторов. В свою очередь, продукция гормонов в ходе развития воспалительного или другого стрессового процесса в значительной мере переходит под контроль цитокинов [32]. Например, в регуляции ГГАК и CHC участвуют такие цитокины как TNF- $\alpha$, IL-1 $\beta$, IL-6. Эти цитокины могут при стрессе продуцироваться не только клетками иммунной системы, но и адренокортикальными клетками. Так что механизмы нейрогуморальной и цитокиновой регуляции тесно переплетены и взаимосвязаны.

MIF имеет ряд особенностей в отношении гормональной регуляции, описанных в ряде обзоров $[19,32,91]$. Физиологический уровень MIF в плазме человека - 2-4 нг/мл, что приблизительно на три порядка выше стрессовой концентрации цитокинов. MIF содержится в передней доле гипофиза в преформированном состоянии в тех же секреторных гранулах, что и АКТГ. При этом MIF обнаруживается в огромных количествах, сопоставимых с содержанием гормонов в клетках этого органа, специализированного для их продукции и внутренней секреции. MIF составляет 0,05\% общего белка передней доли гипофиза (для сравнения - 0,2\% - АКТГ, 0,08 \% - пролактин). Основной стимулятор выделения АКТГ (CRF) способствует транскрипции MIF клетками гипофиза, причем секреция MIF более чувствительна к действию CRF, чем секреция самого АКТГ.

MIF - единственный провоспалительный фактор, чья секреция индуцируется глюкокортикоидами. У ровень сывороточного MIF может значительно повышаться даже при действии высоких доз глюкокортикоидов (до 10-8) - уникальные свойство для цитокинов [56]. Важнейшим иммунорегуляторным свойством MIF является его способность дозозависимым образом отменять иммуносупрессивное действие глюкокортикоидов на синтез и продукцию цитокинов (TNF- $\alpha$, IL-1 $\beta$, IL-6, IL-8, IFN- $\gamma$ ) и пролиферацию Т-клеток, то есть, являться контррегулятором глюкокортикодов в области их физиологических доз. В свою очередь, секреция MIF, индуцированная глюкокортикоидами, находится под жестким контролем этих гормонов, а именно: при высоких дозах глюкокортикоидов (выше $10^{-8} \mathrm{M}$ ) секреция MIF подавляется. При этом глюкокортикоиды супрессируют экспрессию MIF по-разному, в зависимости от типа клеток [4].

Механизм противодействия MIF глюкокортикоидам может осуществляться как минимум тремя способами: 1) через стимуляцию деградации IкB ингибитора NF-кB активации транскрипции провоспалительных цитокинов; 2) через опосредованную ERK1-ERK2-MAPK активацию фосфолипазы A2 (PLA2), являющейся ключевой мишенью ингибирующего действия глюкокортикоидов на индук- цию провоспалительного каскада и 3) через индукцию продукции металлопротеиназ - MMP-1 и MМР-3, синтез которых ингибируется глюкокортикоидами [32].

Таким образом, в отличие от цитокинов, MIF продуцируется не только в результате стресса или хронического воспаления, но и конститутивно, поддерживая при этом регуляторный физиологический баланс с глюкокортикоидами в отношении продукции цитокинов и активации Т-лимфоцитов.

\section{Ферментативные свойства}

Классические цитокины не имеют ферментативных свойств и осуществляют свои функции триггерно, через лиганд-рецепторные взамодействия. Имеются лишь растворимые факторы с цитокиноподобными функциями - тромбин [118], циклофилин [104], FK506-связывающий протеин [68], аденозиндезаминаза [54], нейролейкин [24], NAP-2 [47], которые обладают каталитической ферментативной активностью.

MIF в этом отношении является необычным медиатором, аккумулирующим в себе свойства не только цитокина и гормона, но и фермента. В свою очередь и как фермент MIF также достаточно своеобразен, поскольку обладает, как минимум, двумя ферментативными активностями (см. табл. 5).

По реакционной специфичности фермент MIF можно классифицировать как изомеразу и/или оксидоредуктазу. Показано, что в качестве изомеразы MIF катализирует дофахром-таутомеразную и фенилпируват-таутомеразную реакцию, а также превращения катехоламиноподобных веществ. Тиолпротеин-оксидоредуктазная активность MIF продемонстрирована при восстановлении инсулина глутатионом или дигидролипоамидом. MIF способен также восстанавливать 2-гидроксиэтилдисульфид (HED). MIF связывает глютатион и имеет выраженную гомологию $\mathrm{N}$-концевой аминокислотной последовательности с GSH (глютатион) трансферазой. В 1993 г. Blocki с соавторами [14] было вообще выдвинуто предположение, что MIF может обладать трансферазной активностью. Однако это предположение все еще не получило своего подтверждения.

Постепенно расшифровываются молекулярные механизмы взаимодействия MIF в качестве фермента с рядом молекул. Идентифицированы аминокислоты, участвующие в формировании активного центра таутомеразной ферментативной активности, в частности, $\mathrm{P}^{1}, \mathrm{~K}^{32}, \mathrm{I}^{64}, \mathrm{~N}^{97}, \mathrm{Y}^{95}$ [75]. Установлена последовательность, обеспечивающая оксидоредуктазную активность MIF (мотив CALC), на основании чего MIF оказалось возможным отнести к семейству тиоредоксинов [59].

Несмотря на многочисленные попытки, природные субстраты для ферментативной активности MIF 
пока не обнаружены. С известными субстратами MIF демонстрирует относительно слабую ферментативную активность. Предполагается, что природным субстратом MIF может быть PAG (proliferationassociated gene) - белок с антиоксидантными свойствами.

Можно предположить, что MIF, обладая несколькими разными ферментативными активностями, существенно более низкими по выраженности в сравнении со специализированными ферментами, в эволюционном плане такой же ранний фермент, как и ранний цитокин. Не исключено также, что ферментативные активности MIF, хотя и будучи слабыми, являются составной частью механизмов, необходимых для осуществления внутриклеточных функций этого медиатора.

\section{Регуляция клеточной активности. Сигнальные пути}

Сигнальные пути цитокинов, специализированных сигнальных молекул, опосредующих свои функции через специфические рецепторы, в свою очередь, весьма узко специализированы и эффективны. Наиболее распространенным для цитокинов и ростовых факторов механизмом сигнальной трансдукции является путь, опосредованный белками JAK и STAT. Впервые этот способ передачи сигнала был идентифицирован для интерферонов. Факторы STAT являются членами семейства цитоплазматических транскрипционных факторов, которые опосредуют внутриклеточные сигналы, инициированные цитокинспецифичными рецепторами. STAТ активируются путем фосфорилирования JАК- и МАР-киназами по консервативным остаткам тирозина и серина, соответственно. В результате фосфорилирования молекулы STAT димеризуются и перемещаются в ядро, где регулируют экспрессию генов. В настоящее время охарактеризовано семь членов семейства STAT (STAT-1, -2, -3, -4, -5 $\alpha,-5 \beta,-6)$. Путь JAK/STAT является одним из наиболее быстрых механизмов передачи сигнала из цитоплазмы в ядро. Различные STAT активируются разными группами цитокинов. Например, IFN- $\gamma$ является мощным активатором STAT-1, тогда как члены семейства
IL-6, а также IL-4 и IL-13, активируют главным образом STAT-3. Киназы JAK также имеют определенную специализацию. Рецепторы цитокинов типа I, в состав которых входит субъединица $\gamma_{c}$, активируют JAK1 и JAK3, тогда как рецепторы, включающие субъединицу $\beta_{c}$, - JAK2 [70].

TNF- $\alpha$ индуцирует другой сигнальный путь через стимуляцию NF-кB и активацию JNK (Jun Nterminal kinase)/MAP-киназного каскада. TNF- $\alpha$ является важнейшим индуктором NF-кB. В цитоплазме димеры NF-кB связываются ингибиторными молекулами IкB $(\mathrm{I} \kappa \mathrm{B} \alpha, \mathrm{I} \kappa \mathrm{B} \beta, \mathrm{I \kappa} B \kappa / \varepsilon)$. Последовательные процессы фосфорилирования и протеолиза ІкВ, приводящие к разрушению этого ингибитора, дают возможность димерам NF-кB входить в ядро и индуцировать экспрессию скоординированного набора генов-мишеней, специализированного на регуляции врожденного и адаптивного иммунитета, воспаления, клеточного роста. Сигналы, полученные через рецепторы TNF и стимуляцию NF-кB. включают также программированную смерть клеток [87].

Свое плейотропное воздействие на клетки MIF может осуществлять более разнообразно, пользуясь разными сигнальными путями. Как уже указывалось выше, сигнальная активность MIF может осуществляться рецептор-независимыми путями. Показано, что MIF эндоцитируется как в иммунные, так и в неиммунные клетки, где направляется в цитозоль и в лизосомы. Вход MIF в клетки температуро- и энергозависим, но происходит $\mathrm{Ca}^{2+}$-независимым путем [32]. Этот путь продемонстрирован для опосредованного JAB1 регуляторного действия MIF на пролиферацию фибробластов, их трансформацию и апоптоз (см. табл. 6). Эндоцитированный MIF образует в цитоплазме молекулярный комплекс с JAB1, в результате чего отменяется способность JAB1 активировать JUN N-концевую киназу (JNK). Далее ингибируется фосфорилирование JUN, блокируется его коактивирующее действие на активирующий протеин (AP-1) и последующее формирование гетеротримера JUN-AP-1-FOS. В конечном итоге, стимуляция транскрипции генов провоспалительных цитокинов, вызываемая этим тримером отменяется.

Табл.5. ФЕРМЕНТАТИВНАЯ АКТИВНОСТЬ MIF

\begin{tabular}{|c|c|c|}
\hline $\begin{array}{l}\text { Ферментативная } \\
\text { активность }\end{array}$ & Функция, субстрат & Ссылки \\
\hline \multirow{3}{*}{ Таутомераза } & $\begin{array}{l}\text { Конвертирует D-дофрахромметиловый эфир в 5,6- } \\
\text { дигидрооксихиноидол-2-карбоксиметилэфир }\end{array}$ & {$[12,96]$} \\
\hline & $\begin{array}{l}\text { Катализирует кето-енольную изомеризацию } \\
\text { р-гидроксифенилпирувата и френилпирувата }\end{array}$ & [95] \\
\hline & $\begin{array}{l}\text { Конвертация 3,4-дигидроксифениламинехрома в DHI } \\
\text { 3,5,6-дигидроксииндол и норэпинефринехрома в THI } \\
\text { 3,5,6-тригидроксииндол }\end{array}$ & [78] \\
\hline Оксидоредуктаза & Восстанавливает инсулин и 2-гидроксиэтилдисульфид & {$[60,61]$} \\
\hline
\end{tabular}


Табл.6. СИГНАЛЬНЫЕ ПУТИ И MIF

\begin{tabular}{|c|c|c|c|}
\hline Сигнальный путь & Механизм действия MIF & Результат & Ссылки \\
\hline \multirow[t]{2}{*}{$N F-k B$} & $\begin{array}{l}\text { Снижение уровня цитозольного ІкBa - } \\
\text { ингибитора NF-кB }\end{array}$ & $\begin{array}{l}\text { Контррегуляция } \\
\text { иммуносупрессивной } \\
\text { функции глюкокортикоидов } \\
\text { при LPS-зависимой } \\
\text { стимуляции мононуклеаров } \\
\end{array}$ & {$[30]$} \\
\hline & $\begin{array}{l}\text { MIF увеличивает экспрессию iNOS, в } \\
\text { результате чего возрастает уровень доноров } \\
\text { NO (например, S-нитрозоглутатиона, GSNO), } \\
\text { которые индуцируют экспрессию р53 }\end{array}$ & $\begin{array}{l}\text { Активация апоптоза } \\
\text { макрофрагов }\end{array}$ & {$[32,79]$} \\
\hline \multirow[t]{2}{*}{$\mathrm{Bid} / \mathrm{Bax}$} & $\begin{array}{l}\text { MIF снижает протеолитическое расщепление } \\
\text { факторов Bid и Bax (проапоптозное } \\
\text { семейство Bcl-2), в результате чего } \\
\text { предотвращается выход из митохондрий } \\
\text { цитохрома C и Smac, и, как следствие, } \\
\text { высвобождение каспазы-3 }\end{array}$ & Ингибирование апоптоза & {$[11,23,32]$} \\
\hline & Подавление экспрессии р21 & $\begin{array}{l}\text { Ингибирование экспрессии } \\
\text { р53 и апоптоза }\end{array}$ & [48] \\
\hline \multirow{5}{*}{ MAP2K } & $\begin{array}{l}\text { MIF может ингибировать NO-индуцированное } \\
\text { накопление р53 в макрофрагах посредством } \\
\text { серии активаций ERK1/ERK2-PLA2, COX2 } \\
\text { PGE2; воздействие MIF на этом пути на } \\
\text { индукцию E2F и р53 }\end{array}$ & $\begin{array}{l}\text { Угнетение апоптоза } \\
\text { макрофрагов. Поддержание } \\
\text { роста нормальных и } \\
\text { опухолевых клеток }\end{array}$ & {$[32,90]$} \\
\hline & $\begin{array}{l}\text { MIF связывается c CD74 и индуцирует } \\
\text { следующий каскад фоосфорилирования: } \\
\text { MAP2K, Erk1/2, Elk-1, PI3K, Akt }\end{array}$ & $\begin{array}{l}\text { Ангиогенез и } \\
\text { неоваскуляризация }\end{array}$ & {$[5,22]$} \\
\hline & $\begin{array}{l}\text { MIF связывается с CD74 (или попадает в } \\
\text { клетку путем эндоцитоза) и индуцирует PKA- } \\
\text { зависимое фосфрорилирование ERK1/ERK2, } \\
\text { которое реализуется затем в увеличении } \\
\text { ферментативной активности PLA2 }\end{array}$ & $\begin{array}{l}\text { Индукция PLA2 связана } \\
\text { с индукцией провоспа- } \\
\text { лительного каскада через } \\
\text { контррегуляцию } \\
\text { глюкокортикоидов. } \\
\text { Усиливается продукция } \\
\text { арахидоновой кислоты, и } \\
\text { как следствие, повышается } \\
\text { уровень простагландинов и } \\
\text { лейкотриенов }\end{array}$ & {$[22,81]$} \\
\hline & $\begin{array}{l}\text { MIF индуцирует фосфорилирование р38 и } \\
\text { ERK МАРК }\end{array}$ & $\begin{array}{l}\text { Стимуляция экспрессии } \\
\text { IL-6 через COX-2, } \\
\text { активацию MAPK и } \\
\text { индукция IL-8 через р38 и } \\
\text { ЕRК МАРК-независимый путь } \\
\end{array}$ & [100] \\
\hline & $\begin{array}{l}\text { MIF стимулирует фосфоорилирование } \\
\text { тирозина, аутофоосфорилирование Src, } \\
\text { активацию Ras, активацию ERK1/2, MAPK, но } \\
\text { не JNK или фросфрорилирование c-Jun. }\end{array}$ & $\begin{array}{l}\text { Повышение уровня мРНК } \\
\text { ММР-13 }\end{array}$ & [84] \\
\hline JAB1 & $\begin{array}{l}\text { MIF ингибирует активирующее действие } \\
\text { JAB1 на JNK р27 }{ }^{\text {Kip1 }} \text { посредством } \\
\text { стабилизации белка } 27^{\text {Kip1 }} \\
\end{array}$ & $\begin{array}{l}\text { Регуляция клеточного } \\
\text { цикла }\end{array}$ & {$[58,83]$} \\
\hline STAT-1 & Через р21, циклин 61, Mdm2 & $\begin{array}{l}\text { Регуляция апоптоза, } \\
\text { клеточного цикла }\end{array}$ & {$[28,130]$} \\
\hline PU.1 & $\begin{array}{l}\text { Через семейство транскрипционных } \\
\text { факторов ETS, включая PU.1, критичный для } \\
\text { транскрипции TIr4 у мыши }\end{array}$ & $\begin{array}{l}\text { Экспрессия TLR4, после } \\
\text { чего через активацию NF- } \\
\text { кВ идет активация синтеза } \\
\text { провоспалительных } \\
\text { цитокинов }\end{array}$ & [22] \\
\hline $\begin{array}{l}\text { PKC-, PKA-, Src } \\
\text { family tyrosine } \\
\text { kinase-, MAPK-, } \\
\text { c-Jun-, and AP-1- } \\
\text { зависимые пути } \\
\end{array}$ & 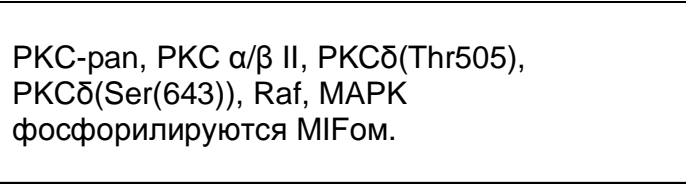 & $\begin{array}{l}\text { Стимулирующая регуляция } \\
\text { продукции индуцированной } \\
\text { ультрафиолетом MMP-1 } \\
\text { мРНК фибробластами } \\
\text { после стимуляции MIF } \\
\end{array}$ & [123] \\
\hline iNOS & $\begin{array}{l}\text { MIF индуцирует активацию iNOS в макро- } \\
\text { фагах и продукцию NO, в отличие от IFN-y } \\
\text { не требует дополнительного сигнала от ЛПС }\end{array}$ & Активация макрофрагов & {$[29,128]$} \\
\hline
\end{tabular}


Табл.7. MIF - СУПЕРЛИГАНД

\begin{tabular}{|c|c|c|c|}
\hline Лиганд для MIF & $\begin{array}{c}\text { Метод определения } \\
\text { связывания }\end{array}$ & Механизм связывания & Ссылка \\
\hline $\begin{array}{l}\text { PAG (Proliferation } \\
\text { associated gene) }\end{array}$ & $\begin{array}{l}\text { Дрожжевая двугибридная } \\
\text { система, использующая LexA } \\
\text { ДНК-связывающий домен MIF } \\
\text { как затравку, } \\
\text { иммуноблоттинг, } \\
\text { коиммунопреципитация }\end{array}$ & $\begin{array}{l}\text { Гетеродимеризация MIF и PAG } \\
\text { с участием консервативных } \\
\mathrm{C}^{52} \text { и } \mathrm{C}^{173} \text { в молекуле PAG, } \\
\text { редокс-зависимая } \\
\text { копреципитация MIF и PAG }\end{array}$ & [51] \\
\hline JAB1 & $\begin{array}{l}\text { Коиммунопреципитация } \\
\text { in vivo, масс-спектрометрия }\end{array}$ & $\begin{array}{l}\text { Связывание с JAB1 } \\
\text { опосредовано а.к.о. 50-56 и C } \\
\text { на молекуле MIF. В свою } \\
\text { очередь, JAB1 связывается с } \\
\text { MIF своим консервативным N- } \\
\text { терминальным доменом Mpr1p } \\
\text { Pad1р (MNP); при этом } \\
\text { функциональный мотив JAMM } \\
\text { во взаимодействие JAB1 с MIF } \\
\text { не вовлекается }\end{array}$ & {$[20,58]$} \\
\hline MHC 1 & $\begin{array}{l}\text { Комплексы HLA-DR c } \\
\text { процессированными } \\
\text { пептидами очищали на } \\
\text { афрфинной колонке, затем } \\
\text { отделяли пептиды кислой } \\
\text { обработкой и проводили их } \\
\text { секвенирование }\end{array}$ & $\begin{array}{l}\text { Аминокислотная } \\
\text { последовательность } \mathrm{Y}^{36} \mathrm{IAV}^{39} \text { в } \\
\text { молекуле MIF взаимодействует } \\
\text { с мотивом FXXL на MHC I. B } \\
\text { результате взаимодействия } \\
\text { MIF презентируется B- } \\
\text { лимфоцитами }\end{array}$ & [129] \\
\hline HLA-DP & $\begin{array}{l}\text { Иммуноаффинная колоночная } \\
\text { хроматография высокого } \\
\text { давления }\end{array}$ & $\begin{array}{l}\text { MIF связывается с } 63-77 \text { а.к.о. } \\
\text { домена } \beta 1 \text { в молекуле HLA-DP }\end{array}$ & [92] \\
\hline HBsAg & ИФА, CD-спектроскопия & $\begin{array}{l}\text { В связывании участвуют 14-33 } \\
\text { а.к.о. в молекуле HBsAg }\end{array}$ & [92] \\
\hline В-цепь инсулина & ИФА, CD-спектроскопия & $\begin{array}{l}\text { В связывании участвуют 9-23 } \\
\text { а.к.о. В-цепи инсулина }\end{array}$ & [92] \\
\hline $\begin{array}{l}\text { Изоформа } \\
\mathrm{Ca}^{2+} / \text { кальмодулин- } \\
\text { зависимой киназы } \\
\text { легкой цепи миозина } \\
\text { (ЕC MLCK) }\end{array}$ & $\begin{array}{l}\text { Дрожжевая двугибридная } \\
\text { система, перекрестная } \\
\text { иммунопреципитация в } \\
\text { неденатурирующих условиях, } \\
\text { глютатион-S-трансферазный } \\
\text { pull-down тест }\end{array}$ & $\begin{array}{l}\text { Образование стабильного } \\
\text { комплекса MIF-MLCK. } \\
\text { Комплекс MIF-MCLK } \\
\text { индуцируется тромбином и } \\
\text { формируется вдоль } \\
\text { периферических стресс- } \\
\text { волокон актина } \\
\end{array}$ & [120] \\
\hline CD74, CD44 & $\begin{array}{l}\text { ИФА, плазменный резонанс в } \\
\text { реальном времени }\end{array}$ & $\begin{array}{l}\text { Олигомеризация CD74 c } \\
\text { участием MIF и CD44 }\end{array}$ & [69] \\
\hline $\begin{array}{l}\text { GSHглютатион } \\
\text { (S-гексилглютатион) }\end{array}$ & $\begin{array}{l}\text { Аффринная хроматография на } \\
\text { колонке с S- гексилглюта- } \\
\text { тионом, ЯMP }\end{array}$ & $\begin{array}{l}\text { MIF имеет структурное } \\
\text { сходство с аминоконцевым } \\
\text { участком } \mu \text {-класса GSH } \\
\text { трансфреразы }\end{array}$ & {$[15,113,122]$} \\
\hline Гематин & $\begin{array}{l}\text { Ингибирование таутомеразной } \\
\text { активности, наша работа - ДСК }\end{array}$ & Не известно & {$[88,133]$} \\
\hline $\begin{array}{l}\text { Ассоциированный с } \\
\text { апоптозом белок } \\
\text { BNIPL }\end{array}$ & $\begin{array}{l}\text { Дрожжевая двугибридная } \\
\text { система, коиммуно- } \\
\text { преципитация in vivo, } \\
\text { глютатион-S-транссреразный } \\
\text { pull-down тест }\end{array}$ & Не известно & [103] \\
\hline L-фрукоза & Афффинная хроматографияя & $\begin{array}{l}\text { MIF связывается c L-фукозой, } \\
\text { входящей в состав кислого } \\
\text { гликолипидного рецептора }\end{array}$ & {$[46]$} \\
\hline $\begin{array}{l}\text { Флавоноиды } \\
\text { (лютеолин, } \\
\text { кверцитин) }\end{array}$ & $\begin{array}{l}\text { Ингибиция таутомеразной } \\
\text { активности }\end{array}$ & $\begin{array}{l}\text { Подобен связыванию } \\
\text { катехоламиновых } \\
\text { флавоноидов эстроген- } \\
\text { индуцируемыми } \\
\text { связывающими сайтами типа II }\end{array}$ & [43] \\
\hline
\end{tabular}


Связывание MIF c JAB1 препятствует также связыванию последнего с $\mathrm{p} 27^{\mathrm{KIP}} 1$, ингибитором клеточного цикла, в результате чего отменяется стимулирующее для роста клеток действие JАВ1. В целом установлено, что в высоких концентрациях MIF, образуя комплекс JAB1, выступает как ингибитор пролиферации фибробластов и продукции ими провоспалительных цитокинов [58].

Напротив, на сигнальном пути регуляции клеточной активности, происходящем не посредством эндоцитоза, а через «рецептор» CD74, MIF стимулирует покоящиеся фибробласты к размножению, индуцируя как быструю (в пределах 30 минут), так и замедленную (до 24 часов) активацию пути ERK1ERK2-MAPK. Кроме того, на этом пути воздействие MIF приводит также к увеличению активности PLA2, к активации провоспалительного каскада, ведущего к продукции арахидоновой кислоты и продуктов ее метаболизма - простагландинов и лейкотриенов.

Противоположные эффекты MIF может оказывать и на апоптоз макрофагов. Увеличение экспрессии iNOS, сопровождающее вызванную MIF активацию NF-кB, может приводить к возрастанию уровня доноров $\mathrm{NO}$, которые стимулируют р53-зависимый апоптоз. В то же время, MIF способен ингибировать NO-индуцированное накопление р53 в макрофагах в результате серии активаций ERK1/ ERK2, PLA2, COX2 и $\mathrm{PGE}_{2}$. В этом случае апоптоз макрофагов ингибируется (см. табл. 6).

Таким образом, MIF оказывает на одни и те же клетки-мишени альтернативные эффекты, механизмы которых могут быть различными: определяться концентрацией MIF, направлением сигнального пути, а также участием рецепторов.

В целом, многообразие сигнальных путей, посредством которых MIF может оказывать регуляторное действие на клетки, с учетом его постоянного присутствия внутри клетки и поступления извне посредством эндоцитоза, указывает на многовектор- ность реализации возможностей этого фактора при осуществлении его функций в условиях нормы и стресса.

\section{Лигандные свойства}

Как уже указывалось выше, провоспалительные цитокины характеризуются тем, что могут продуцироваться самыми разнообразными клетками организма в ответ на стресс-стимул, с одной стороны, и тем, что связываются со специализированными рецепторами на поверхности клеток, с другой. Связывание происходит как со специализированными доменами этих рецепторов, так и с общими для нескольких цитокиновых рецепторов субъединицами $\left(\gamma_{c}, \beta_{\mathrm{c}}\right.$ и gp130). Спектр специализированных молекул, с которыми связываются цитокины, весьма ограничен. Именно в силу высокой избирательности рецепторов провоспалительные цитокины могут быть функционально активны в весьма низких концентрациях (от нескольких пг/мл и выше).

Напротив, MIF проявляет свойства суперлиганда. Уже к настоящему времени установлен длинный список биологически важных лигандов, с которыми связывается MIF. Далеко не исчерпывающая часть этого списка представлена в таблицах 7 и 8 .

Функциональное значение взаимодействия MIF с рядом веществ пока еще не достаточно изучено. Предполагается, что гетеродимеризация MIF c PAG, возможно, регулирует антиоксидантную активность последнего [32]. Показано, что связывание с JAB1 модулирует ряд внутриклеточных сигналов, регулирует клеточный цикл $[20,51]$.

Взаимодействие MIF со свободным гематином (при повышении его концентрации выше физиологической) может активировать MIF и стимулировать презентацию антигенов [88]. Осуществлению последней может способствовать прямое физическое взаимодействие MIF c CD74 [69]. Показано, что MIF, взаимодействуя с презентируемым пептидом,

ТабЛ.8. МОДУЛЯЦИЯ КЕТО-ЕНОЛ ИЗОМЕРАЗНОЙ АКТИВНОСТИ РЕКОМБИНАНТНОГО RМІF2З (СУБСТРАТ - 0,5 ММ ГИДРОКСИФЕНИЛ ПИРУВАТ)

\begin{tabular}{|c|c|c|}
\hline Субстанция & Концентрация & \% от контр. активности \\
\hline \multicolumn{3}{|c|}{ Ингибиторы } \\
\hline Гемин & 1 мкM & 27 \\
\hline Гепарин & 25 МЕ/мЛ & 60 \\
\hline Меркаптоэтанол & 100 мM & 43 \\
\hline L-цистеин & $100 \mathrm{mM}$ & 54 \\
\hline Глутатион восст. (GSH) & $100 \mathrm{mM}$ & 70 \\
\hline р-гидроксифенил уксусная кислота* & $1 \mathrm{mM}$ & 53 \\
\hline \multicolumn{3}{|c|}{ Активаторы } \\
\hline Гентамицин & 80 мкг/мл & 248 \\
\hline $\mathrm{HBsAg}$ & 7 мкг/мл & 160 \\
\hline \multicolumn{3}{|c|}{ Нейтральные вещества } \\
\hline $\begin{array}{l}\text { L-фрукоза } \\
\text { lgG }\end{array}$ & $5 \mathrm{mM}$ & $\begin{array}{l}100 \\
100\end{array}$ \\
\hline
\end{tabular}

*конкурентный ингибитор 
например, с HBsAg или В-цепью инсулина, может проявлять шаперонные свойства, содействуя правильной укладке пептида в ложе молекулы $\mathrm{MHC}$ класса II [69].

Интересно, что MIF при лигандном взаимодействии с HLA II (HLA-DP) эндоцитируется. Внешне этот механизм подобен способу попадания внутрь клетки молекул gp97, Hsp90 и Нsp70 и калоретикулина через рецептор CD91 [92].

Кроме того, установлено, MIF образует комплекс c MHC класса I и что формирование комплекса опосредовано взаимодействием участка MIF с аминокислотной последовательностью $\mathrm{Y}^{36} \mathrm{IAV}^{39}$ с мотивом FXXL на молекуле MHC[129].

Обнаружение возможности образования комплекса MIF с зависимой от $\mathrm{Ca}^{2+}$ - миозинкиназой (EC MLCK) указало на механизм вовлеченности MIF в регуляцию динамики цитоскелета клеток эндотелия, в частности, клеток эндотелия сосудов. Предполагается, что избыток MIF в клетках эндотелия может быть одной из причин развития патобиологических процессов в сосудах (120). Не исключено, что в $\mathrm{Ca}^{2+}$-зависимой регуляции цитоскелета участвуют два MIF-родственных протеина - MRP8 (S100A8) и MRP14 (S100A9) [55, 131], которые, со своей стороны, также комплексируются с MIF [131].

Мы провели ряд исследований, посвященных изучению модулирующего действия ряда веществ на таутомеразную активность MIF (в качестве субстрата использовали р-гидроксифенилпируват) [133]. В работе использовались высокоочищенные рекомбинантные и природные формы MIF. Мы обнаружили ряд веществ (гемин, гепарин, меркаптоэтанол, L-цистеин и GSH), которые при связывании c MIF неконкурентным образом ингибируют его таутомеразную активность. При связывании MIF c гемином происходит изменение конформации MIF, что подтверждено методом дифференциальной сканирующей калориметрии [133]. Нами обнаружен природный конкурентный ингибитор таутомеразной активности MIF р-гидроксифенилуксусная кислота (ПГФУК). Мы установили также, что гентамицин и $\mathrm{HBsAg}$ могут активировать таутомеразную активность рекомбинантного MIF. Ранее в литературе не было описано существование веществ, способных вызвать активацию таутомеразной функции y MIF. Полученные нами данные являются интригующими еще и потому, что гентамицин - широко применяемое терапевтическое средство, a HBsAg вирусный антиген, в презентации которого MIF может принимать шаперонное участие.

Кроме того, наши эксперименты показали, что Lфукоза, с которой связывается MIF так что при этом отменяется его способность к подавлению миграции макрофагов [46], не влияет на таутомеразную активность MIF. На ферментативную кето-енол изомеразную активность не влияет и обнаруженное нами высокоэффективное связывание MIF с иммуноглобулином G.

Bсе перечисленные факты указывают, что MIF проявляет свойства суперлиганда, то есть может, в отличие от цитокинов, связываться с большим количеством разнообразных веществ. Это связывание способно тем или иным образом повлиять на отдельные функциональные активности MIF, например, на его ферментативную активность.

Для более точного понимания роли и механизмов участия MIF в локальной и системной регуляции организма в условиях нормы и стресс-мобилизации представляется перспективным проведение дальнейших исследований лигандных свойств MIF. Такие исследования, проводимое с целью более корректного определения функционального значения вновь образованных связей MIF с лигандами, должно осуществляться с максимально широким набором взаимодействующих с ним веществ. Оно будет результативным, если будет сопровождаться углубленной характеристикой лигандных взаимодействий физико-химическими методами, сравнительным изучением вызванных связыванием с лигандом модификаций ферментативных и биологических функций MIF, прецизионным картированием специализированных участков молекулы MIF, образующих лигандные связи, методом мутантного и пептидного анализа.

\section{Заключение}

Сравнение цитокинов и MIF по основным общебиологическим свойствам показывает наличие у них, как сходства, так и существенных различий. И сходство и различия носят фундаментальный характер.

Цитокины - это сравнительно специализированные сигнальные молекулы, предназначенные для взаимодействия со специфическими рецепторами, результатом которого является включение определенных сигнальных путей и дальнейшая реализация генетической программы по формированию защитного ответа организма (врожденного и адаптивного) против воспалительного или другого стрессового воздействия. Сообщество семейств цитокинов в эволюции возникло и развивалось параллельно развитию иммунной системы и послужило биологической основой для формирования более «интеллектуальной» системы иммунного распознавания и адаптивного иммунитета. Эти семейства функционируют в виде «цитокиновой сети» - спектра неспецифических регуляторных молекул, межклеточных растворимых медиаторов, действующих как локально, так и дистантно.

MIF может быть по совокупности своих свойств включен в сообщество цитокинов, прежде всего, провоспалительных, а также ростовых факторов. 
MIF и провоспалительные цитокины реализуют свои активности на одном и том же функциональном «поле», в едином плейотропном механизме запуска и развития защитной стресс-реакции организма. Среди провоспалительных цитокинов MIF выделяется широтой своего функционального потенциала. Он как бы менее специализирован, но более универсален. То есть он выполняет ряд тех же функций, которые обеспечивают цитокины, но часто не столь эффективно, как эти специализированные молекулы.

В то же время, MIF отличается от цитокинов, прежде всего, древностью своего происхождения в эволюции. Он появляется уже у растений и бактерий, высоко консервативен по первичной структуре и имеет уникальную третичную структуру, гомологи которой имеются только у низших животных, MIF характеризуется разнообразием самых общих биологических функций - цитокин, фермент, гормон, множеством способов реализации своих активностей, путей проникновения в клетку, внутри которой он себя чувствует «как дома». Характеризуется MIF также своей способностью связываться с целым спектром различных биологически важных молекул. Название этого плейотропного фактора - MIF, происходящее от его всего лишь одной из многочисленных функций - подавления миграции макрофагов, явно устарело. Поскольку основные молекулярные механизмы реализации его функций остаются неизвестными, феноменологически его можно было бы переименовать в эоцитокин (от греческого ео- ранний) или просто эокин. Действительно, MIF - защитный стресс-белок, который: 1) появляется очень рано в эволюции, 2) обнаруживается в онтогенезе на самых ранних этапах, 3) вступает в формирование защитного ответа на самых ранних этапах - уже в первые минуты, 4) в осуществление своих функций опирается на самые древние механизмы - различные ферментативные активности, в том числе, и на окислительно-восстановительные, и, наконец, 5) обладает способностью функционально значимого связывания с большим разнообразием биологических веществ. В свою очередь, распространение MIF в организме носит повсеместный характер, он постоянно присутствует в циркуляции в относительно высоких концентрациях, способных оказать разнообразные физиологические функции, включая контррегулирующее действие на иммуносупрессивное действие глюкокортикоидов. Таким образом, MIF является не только провоспалительным медиатором, реализующим свой мобилизационный потенциал на самых ранних этапах развития защитных реакций, но и постоянно действующим физиологическим фактором. Представляется, что, исходя из регуляторного потенциала MIF, общепринятое понятие «естественной резистентности» можно расширить до понятия «есте- ственной устойчивости», в поддержании которой как на уровне клетки, так и на уровне организма MIF может играть ключевую роль. Истинное назначение MIF - этого древнего и в то же время «вечно юного» фактора, исключительно удачно встроенного в среду самых «продвинутых» защитных систем организма, включая адоптивную иммунную системы - будет определено лишь в результате дальнейших исследований, которые проводятся в настоящее время в мире исключительно интенсивно.

\section{Список литературы}

1. Abe R., Peng T., Sailors J., Bucala R., Metz C.N. Regulation of the CTL response by macrophage migration inhibitory factor // J. Immunol.-2001.-Vol.166, №2.-P.747-753.

2. Abe R., Shimizu T., Ohkawara A., Nishihira J. Enhancement of macrophage migration inhibitory factor (MIF) expression in injured epidermis and cultured fibroblasts // Biochim. Biophys. Acta -2000.-Vol.1500, №1.-P.1-9.

3. Akoum A., Metz C.N., Morin M. Marked increase in macrophage migration inhibitory factor synthesis and secretion in human endometrial cells in response to human chorionic gonadotropin hormone // J. Clin. Endocrinol. Metab.-2005.-Vol.90, №5.-P.2904-2910.

4. Alourfi Z., Donn R., Stevens A., Berry A., McMaster A., Ray D. Glucocortikoids suppress macrophage migration inhibitory factor (MIF) expression in a cell-type-specific manner // J. Mol. Endocrinol.-2005.V.34. - № 2.- P. 583-595.

5. Amin M.A., Volpert O.V., Woods J.M., Kumar P., Harlow L.A., Koch A.E. Migration inhibitory factor mediates angiogenesis via mitogen-activated protein kinase and phosphatidylinositol kinase // Circ. Res.2003.-Vol.93, №4.-P.321-329.

6. Angeli A., Masera R.G., Sartori M.L., Fortunati N., Racca S., Dovio A., Staurenghi A., Frairia R. Modulation by cytokines of glucocorticoid action // Ann. N. Y. Acad. Sci.-1999.-Vol.876.-P.210-220.

7. Apte R.S., Sinha D., Mayhew E., Wistow G.J., Niederkorn J.Y. Cutting edge: role of macrophage migration inhibitory factor in inhibiting NK cell activity and preserving immune privilege // J. Immunol.-1998.Vol.160, №12.-P.5693-5696.

8. Arcuri F., Cintorino M., Vatti R., Carducci A., Liberatori S., Paulesu L. Expression of macrophage migration inhibitory factor transcript and protein by first-trimester human trophoblasts // Biol. Reprod.1999.-Vol.60, №6.-P.1299-1303.

9. Bacher M., Metz C.N., Calandra T., Mayer K., Chesney J., Lohoff M., Gemsa D., Donnelly T., Bucala R. An essential regulatory role for macrophage migration inhibitory factor in T-cell activation // PNAS1996.-Vol.93.-P.7849-7854.

10. Bacher M., Schrader J., Thompson N., Kuschela K., Gemsa D., Waeber G., Schlegel J. Up-regulation of macrophage migration inhibitory factor gene and protein expression in glial tumor cells during hypoxic and 
hypoglycemic stress indicates a critical role for angiogenesis in glioblastoma multiforme // Am. J. Pathol.2003.-Vol.162, №1-P.11-17.

11. Baumann R., Casaulta C., Simon D., Conus S., Yousefi S., Simon H.U. Macrophage migration inhibitory factor delays apoptosis in neutrophils by inhibiting the mitochondria-dependent death pathway // FASEB J.-2003.-Vol.17, №15.-P.2221-2230.

12. Bendrat K., Al-Abed Y., Callaway D.J., Peng T., Calandra T., Metz C.N., Bucala R. Biochemical and mutational investigations of the enzymatic activity of macrophage migration inhibitory factor // Biochemistry.-1997.-Vol.36, №49.-P.15356-15362.

13. Benigni F., Atsumi T., Calandra T., Metz C., Echtenacher B., Peng T., Bucala R. The proinflammatory mediator macrophage migration inhibitory factor induces glucose catabolism in muscle // J. Clin. Invest.2000.-Vol.106, №10.-P.1291-300.

14. Blocki F.A., Ellis L.B., Wackett L.P. MIF protein are theta-class glutathione $\mathrm{S}$-transferase homologs // Protein Sci.-1993.-Vol.2, №12.-P.2095-2102.

15. Blocki F.A., Schlievert P.M., Wackett L.P. Rat liver protein linking chemical and immunological detoxification systems // Nature-1992.-Vol.360, №6401.P.269-270.

16. Bloom B.R., Bennet B. Mechanism of reaction in vitro associated with delayed-type hypersensitivity // Science-1966.-Vol.153.-P.80-82.

17. Bornstein S.R., Chrousos G.P. Adrenocorticotropin (ACTH)- and non-ACTH-mediated regulation of the adrenal cortex: neural and immune inputs // J. Clin. Endocrinol. Metab.-1999.-Vol.84, №5.-P.1729-1736.

18. Brown F.G., Nikolic-Paterson D.J., Chadban S.J., Dowling J., Jose M., Metz C.N., Bucala R., Atkins R.C. Urine macrophage migration inhibitory factor concentrations as a diagnostic tool in human renal allograft rejection // Transplantation-2001.-Vol.71, №12.P.1777-1783.

19. Bucala R. Neuroimmunomodulation by macrophage migration inhibitory factor (MIF) // Ann. N.Y. Acad. Sci.-1998.-Vol.840, №1.-P.74-82.

20. Burger-Kentischer A., Finkelmeier D., Thiele M., Schmucker J., Geiger G., Tovar G.E., Bernhagen J. Binding of JAB1/CSN5 to MIF is mediated by the MPN domain but is independent of the JAMM motif / / FEBS Lett.-2005.-Vol.579, №7.-P.1693-1701.

21. Calandra T., Bernhagen J., Metz C.N., Spiegel L.A., Bacher M., Donnelly T., Cerami A., Bucala R. MIF as a glucocorticoid-induced modulator of cytokine production // Nature-1995.-Vol.377.-P.68-71.

22. Calandra T., Roger T. Macrophage migration inhibitory factor: a regulator of innate immunity / / Nat. Rev. Immunol.-2003.-Vol.3, №10.-P.791-800.

23. Chagnon F., Metz C.N., Bucala R., Lesur O. Endotoxin-induced myocardial dysfunction: effects of macrophage migration inhibitory factor neutralization // Circ. Res.-2005.-Vol.96, №10.-P.1095-1102.

24. Chaput M., Claes V., Portetelle D., Cludts I., Cravador A., Burny A., Gras H., Tartar A. The neurotrophic factor neuroleukin is $90 \%$ homologous with phosphohexose isomerase // Nature-1988.-Vol.332, №6163.-P.454-455.

25. Chen Z., Sakuma M., Zago A.C., Zhang X., Shi C., Leng L., Mizue Y., Bucala R., Simon D.I. Evidence for a role of macrophage migration inhibitory factor in vascular disease // Arterioscler. Thromb. Vasc. Biol.2004.-Vol.24.-P.709-714.

26. Chesney J., Metz C., Bacher M., Peng T., Meinhardt A., Bucala R. An essential role for macrophage migration inhibitory factor (MIF) in angiogenesis and growth of a murine lymphoma // Mol. Med.-1999.Vol.5, №3.-P.181-191.

27. Collette Y., Gilles A., Pontarotti P., Olive D. A co-evolution perspective of the TNFSF and TNFRSF families in the immune system // Trends Immunol.2003.-Vol. 24, №7.-P.387-394.

28. Cordon-Cardo C., Prives C. At the crossroads of inflammation and tumorigenesis // J. Exp. Med.1999.-Vol.190, №10.-P.1367-1370.

29. Cunha F.Q., Weiser W.Y., David J.R., Moss D.W., Moncada S., Liew F.Y. Recombinant migration inhibitory factor induces nitric oxide synthase in murine macrophages // J. Immunol.-1993.-Vol.150, №5.P.1908-1912.

30. Daun J.M., Cannon J.G. Macrophage migration inhibitory factor antagonizes hydrocortisone-induced increases in cytosolic IкB $\alpha / /$ Am. J. Physiol. Regul. Integr. Comp. Physiol.-2000.-Vol.279, №3.-P.R1043R1049.

31. David J.R. Delayed hypersensitivity in vitro. The modulation by cell-free substances formed by lymphoid cell-antigen interaction // PNAS - 1966.- Vol.56.P.72-77.

32. Denkinger C.M., Metz C., Fingerle-Rowson G., Denkinger M.D., Forsthuber T. Macrophage migration inhibitory factor and its role in autoimmune diseases / / Arch. Immunol. Ther. Exp.-2004.-Vol.52, №6.-P.389400.

33. Donn R.P., Ray D.W. Macrophage migration inhibitory factor: molecular, cellular and genetic aspects of a key neuroendocrine molecule // J. Endocrinol.2004.-Vol.182.-P.1-9.

34. Donnelly S.C., Haslett C., Reid P.T., Grant I.S., Wallace W.A., Metz C.N., Bruce L.J.,Bucala R. Regulatory role for macrophage migration inhibitory factor in acute respiratory distress syndrome // Nat. Med.1997.-Vol.3, №3.-P.320-323.

35. Ealick S.E., Cook W.J., Vijay-Kumar S., Carson M., Nagabhushan T.L., Trotta P.P., Bugg C.E. Three-dimensional structure of recombinant human interferongamma // Science-1991.-Vol.252, №5006.-P.698-702.

36. Eickhoff R., Baldauf C., Koyro H.W., Wennemuth G., Suga Y., Seitz J., Henkel R., Meinhardt A. Influence of macrophage migration inhibitory factor (MIF) on the zinc content and redox state of proteinbound sulphydryl groups in rat sperm: indications for a new role of MIF in sperm maturation // Mol. Hum. Reprod.-2004.-Vol.10, №8.-P.605-611.

37. Esumi N., Budarf M., Ciccarelli L., Sellinger B., Kozak C.A., Wistow G. Conserved gene structure and 
genomic linkage for D-dopachrome tautomerase (DDT) and MIF // Mamm. Genome.-1998.-Vol.9, №9.-P.753-757.

38. Fingerle-Rowson G., Koch P., Bikoff R., Lin X., Metz C.N., Dhabhar F.S., Meinhardt A.,Bucala R. Regulation of macrophage migration inhibitory factor expression by glucocorticoids in vivo // Am. J. Pathol.2003.-Vol.162, №1.-P.47-56.

39. Fingerle-Rowson G., Petrenko O., Metz C.N., Forsthuber T.G., Mitchell R., Huss R., Moll U., Muller W., Bucala R. The p53-dependent effects of macrophage migration inhibitory factor revealed by gene targeting // PNAS-2003.-Vol.100, №16.-P.9354-9359.

40. Flieger O., Engling A., Bucala R., Lue H., Nickel W., Bernhagen J. Regulated secretion of macrophage migration inhibitory factor is mediated by a non-classical pathway involving an ABC transporter // FEBS Lett.-2003.-Vol.551, №1-3.-P.78-86.

41. Fukuzawa J., Nishihira J., Hasebe N., Haneda T., Osaki J., Saito T., Nomura T., Fujino T., Wakamiya N., Kikuchi K. Contribution of macrophage migration inhibitory factor to extracellular signal-regulated kinase activation by oxidative stress in cardiomuocytes // J. Biol. Chem.-2002.-Vol.277, №28.-P.24889-24895.

42. Galat A., Riviere S., Bouet F., Menez A. A diversified family of 12-kDa proteins with a high amino acid sequence similarity to macrophage migration-inhibitory factor (MIF) // Eur. J. Biochem.-1994.-Vol.224, №2.P.417-421.

43. Garai J., Adlercreutz H. Estrogen-inducible uterine flavonoid binding sites: is it time to reconsider? // J. Steroid. Biochem Mol. Biol.-2004.-Vol.88, №4-5.-P.377-381.

44. Goetz F.W., Planas J.V., MacKenzie S. Tumor necrosis factors // Dev. Comp. Immunol.-2004.-Vol.28, №5.-P.487-497.

45. Herriott M.J., Jiang H., Stewart C.A., Fast D.J., Leu R.W. Mechanistic differences between migration inhibitory factor (MIF) and IFN- $\gamma$ for macrophage activation // J. Immunol.-1993.-Vol.150, 110.-P.4524-4531.

46. Higgins T.J., Liu D.Y., Remold H.G., David J.R. Further characterization of the putative glycolipid receptor for MIF: role of fucose associated with an acidic glycolipid // Biochem. Biophys. Res. Commun.-1980.Vol.93, №4.-P.1259-1265.

47. Hoogewerf A.J., Leone J.W., Reardon I.M., Howe W.J., Asa D., Heinrikson R.L., Ledbetter S.R. CXC chemokines connective tissue activating peptide-III and neutrophil activating peptide- 2 are heparin/heparan sulfate-degrading enzymes // J. Biol. Chem.-1995.Vol.270, №7.-P.3268-3277.

48. Hudson J.D., Shoaibi M.A., Maestro R., Carnero A., Hannon G.J., Beach D.H. A proinflammatory cytokine inhibits p53 tumor suppressor activity // J. Exp. Med.-1999.-Vol.190, №10.-P.1375-1382.

49. Jaworski D.C., Jasinskas A., Metz C.N., Bucala R., Barbour A.G. Identification and characterization of a homologue of the pro-inflammatory cytokine Macrophage Migration Inhibitory Factor in the tick, Amblyomma americanum // Insect. Mol. Biol.-2001.Vol.10, №4.-P.323-331.
50. Josephson K., DiGiacomo R., Indelicato S.R., Iyo A.H., Nagabhushan T.L., Parker M.H., Walter M.R. Design and analysis of an engineered human interleukin-10 monomer // J. Biol. Chem.-2000.-Vol.275, №18.-P.13552-13557.

51. Jung H., Kim T., Chae H.Z., Kim K.T., Ha H. Regulation of macrophage migration inhibitory factor and thiol-specific antioxidant protein PAG by direct interaction // J. Biol. Chem.-2001.-Vol.276, №18.P.15504-15510.

52. Juttner S., Bernhagen J., Metz C.N., Rollinghoff M., Bucala R., Gessner A. Migration inhibitory factor induces killing of Leishmania major by macrophages: dependence on reactive nitrogen intermediates and endogenous TNF- $\alpha$ // J. Immunol.-1998.-Vol.161.-P.2383-2390.

53. Kaiser P., Rothwell L., Avery S., Balu S. Evolution of the interleukins // Dev. Comp. Immunol.-2004.Vol.28, №5.-P.375-394.

54. Kameoka J., Tanaka T., Nojima Y., Schlossman S.F., Morimoto C. Direct association of adenosine deaminase with a T cell activation antigen, CD26 // Science-1993.-Vol.261, №5120.-P.466-469.

55. Kerkhoff c., Klempt M., Sorg. Novel insights into structure and function of MRP8 (S100A8) and MRP14 (S100A9). // Biochim. Biophys. Acta.-1998.-V.1448.No2.-P.200-211.

56. Kitaichi N., Kotake S., Mizue Y., Sasamoto Y., Goda C., Iwabuchi K., Onoe K., Matsuda H., Nishihira J. High-dose corticosteroid administration induces increase of serum macrophage migration inhibitory factor in patients with Vogt-Koyanagi-Harada's disease / / Microbiol. Immunol.-2000.-Vol.44, №12.-P.10751077.

57. Kleemann R., Grell M., Mischke R., Zimmermann G., Bernhagen J. Receptor binding and cellular uptake studies of macrophage migration inhibitory factor (MIF): use of biologically active labeled MIF derivatives // J. Interferon. Cytokine Res.-2002.-Vol.22, №3.-P.351-363.

58. Kleemann R., Hausser A., Geiger G., Mischke R., Burger-Kentischer A., Flieger O., Johannes F.J., Roger T., Calandra T., Kapurniotu A., Grell M., Finkelmeier D., Brunner H., Bernhagen J. Intracellular action of the cytokine MIF to modulate AP-1 activity and the cell cycle through Jab1 // Nature-2000.Vol.408, №6809.-P.211-216.

59. Kleemann R., Kapurniotu A., Frank R.W., Gessner A., Mischke R., Flieger O., Juttner S., Brunner H., Bernhagen J. Disulfide analysis reveals a role for macrophage migration inhibitory factor(MIF) as thiol-protein oxidoreductase // J. Mol. Biol.-1998.-Vol.280, №1.-P.85-102.

60. Kleemann R., Kapurniotu A., Mischke R., Held J., Bernhagen J. Characterization of catalytic centre mutants of macrophage migration inhibitory factor (MIF) and comparison to Cys81Ser MIF // Eur. J. Biochem.-1999.-Vol.261, №3.-P.753-766.

61. Kleemann R., Mischke R., Kapurniotu A., Brunner H., Bernhagen J. Specific reduction of insulin disulfides by macrophage migration inhibitory factor 
(MIF) with glutathione and dihydrolipoamide: potential role in cellular redox processes / / FEBS Lett.-1998.Vol.430, №3.-P.191-196.

62. Kultz D. Evolution of the cellular stress proteome: from monophyletic origin to ubiquitous function // J. Exp. Biol.-2003.-Vol.206, Pt.18.-P.3119-24.

63. Kuriyama T., Fujinaga M., Koda T., Nishihira J. Cloning of the mouse gene for D-dopachrome tautomerase // Biochim. Biophys. Acta.-1998.-Vol.1388, №2.-P.506-512.

64. Laing K.J., Secombes C.J. Chemokines // Dev. Comp. Immunol.-2004.-Vol.28, №5.-P.443-460.

65. Lan H.Y., Bacher M., Yang N., Mu W., NikolicPaterson D.J., Metz C., Meinhardt A., Bucala R., Atkins R.C. The pathogenic role of macrophage migration inhibitory factor in immunologically induced kidney disease in the rat // J. Exp. Med.-1997.-Vol.185, №8.-P.1455-1465.

66. Lanahan A., Williams J.B., Sanders L.K., Nathans D. Growth factor-induced delayed early response genes // Mol. Cell. Biol.-1992.-Vol.12, №9.-P.3919-3929.

67. Lechmann L., Weber S., Fuchs D., Klaschik S., Shewe J., Book M., Hoeft A., Stuber F. // Free Radic. Biol. Med.-2005.-V. 38.-№9.-P.117-1179.

68. Leiva M.C., Lyttle C.R. Leukocyte chemotactic activity of FKBP and inhibition by FK506 // Biochem. Biophys. Res. Commun.-1992.-Vol.186, №2.-P.11781183.

69. Leng L., Metz C.N., Fang Y., Xu J., Donnelly S., Baugh J., Delohery T., Chen Y., Mitchell R.A., Bucala R. MIF signal transduction initiated by binding to CD74 // J. Exp. Med.-2003.-Vol.197, №11.-P.1467-1476.

70. Leonard W.J. Cytokines and immunodeficiency disease // Nature Rew.-2001.-Vol.1.-P.200-208.

71. Leung J.C., Chan L.Y., Tsang A.W., Liu E.W., Lam M.F., Tang S.C., Lai K.N. Anti-macrophage migration inhibitory factor reduces transforming growthfactor-beta 1 expression in experimental IgA nephropathy // Nephrol. Dial. Transplant.-2004.-Vol.19, №8.P.1976-1985.

72. Li Z., Ren Y., Wu Q.C., Lin S.X., Liang Y.J., Liang H.Z. Macrophage migration inhibitory factor enhances neoplastic cell invasion by inducing the expression of matrix metalloproteinase 9 and interleukin- 8 in nasopharyngeal carcinoma cell lines // Chin. Med. J. (Engl).-2004.-Vol.117, №1.-P.107-114.

73. Lin S.G., Yu X.Y., Chen Y.X., Huang X.R., Metz C., Bucala R., Lau C.P., Lan H.Y. De novo expression of macrophage migration inhibitory factor in atherogenesis in rabbits // Circ. Res.-2000.-Vol.87, №12.P.1202-1208.

74. Lolis E., Bucala R. Macrophage migration inhibitory factor // Expert. Opin. Ther. Targets.-2003.Vol.7, №2.-P.153-164.

75. Lubetsky J.B., Dios A., Han J., Aljabari B., Ruzsicska B., Mitchell R., Lolis E., Al-Abed Y. The tautomerase active site of macrophage migration inhibitory factor is a potential target for discovery of novel antiinflammatory agents // J. Biol. Chem.-2002.-Vol.277, №28.-24976-24982.
76. Makita H., Nishimura M., Miyamoto K., Nakano T., Tanino Y., Hirokawa J., Nishihira J., Kawakami Y. Effect of anti-macrophage migration inhibitory factor antibody on lipopolysaccharide-induced pulmonary neutrophil accumulation // Am. J. Respir. Crit. Care. Med.-1998.-Vol.158, №2.-P.573-579.

77. Marson AL, Tarr DE, Scott AL. Macrophage migration inhibitory factor (mif) transcription is significantly elevated in Caenorhabditis elegans dauer larvae // Gene-2001.-Vol.278, №1-2.-P.53-62.

78. Matsunaga J., Sinha D., Pannell L., Santis C., Solano F., Wistow G.J., Hearing V.J. Enzyme activity of macrophage migration inhibitory factor toward oxidized catecholamines // J. Biol. Chem.-1999.-Vol.274, №6.-P.3268-3271.

79. Messmer U.K., Brune B. Nitric oxide-induced apoptosis: p53-dependent and p53-independent signaling pathways // Biochem. J.-1996.-Vol.319, Pt.1.P.299-305.

80. Mikayama T., Nakano T., Gomi H., Nakagawa Y., Liu Y.C., Sato M., Iwamatsu A., Ishii Y., Weiser W.Y., Ishizaka K. Molecular cloning and functional expression of a cDNA encoding glycosylation-inhibiting factor // PNAS-1993.-Vol.90, №21.-P.1005610060.

81. Mitchell R.A., Metz C.N., Peng T., Bucala R. Sustained mitogen-activated protein kinase (MAPK) and cytoplasmic phospholipase A2 activation by macrophage migration inhibitory factor (MIF). Regulatory role in cell proliferation and glucocorticoid action / / J. Biol. Chem.-1999.-Vol.274, №25.-P.18100-18106.

82. Nguyen M.T., Beck J., Lue H., Funfzig H., Kleemann R., Koolwijk P., Kapurniotu A.,Bernhagen J. A 16-residue peptide fragment of macrophage migration inhibitory factor, MIF-(50-65), exhibits redox activity and has MIF-like biological functions // J. Biol. Chem.-2003.-Vol.278, №36.-P.33654-33671.

83. Nguyen M.T., Lue H., Kleemann R., Thiele M., Tolle G., Finkelmeier D., Wagner E., Braun A., Bernhagen J. The cytokine macrophage migration inhibitory factor reduces pro-oxidative stress-induced apoptosis // J. Immunol.-2003.-Vol.170, №6.-P.3337-3347.

84. Onodera S., Nishihira J., Iwabuchi K., Koyama Y., Yoshida K., Tanaka S., Minami A. Macrophage migration inhibitory factor up-regulates matrix metalloproteinase-9 and -13 in rat osteoblasts. Relevance to intracellular signaling pathways // J. Biol. Chem.2002.-Vol.277, №10.-P.7865-7874.

85. Onodera S., Suzuki K., Matsuno T., Kaneda K., Takagi M., Nishihira J. Macrophage migration inhibitory factor induces phagocytosis of foreign particles by macrophages in autocrine and paracrine fashion // Immunology-1997.-Vol.92.-P.131-137.

86. Ottaviani E., Malagoli D., Franchini A. Invertebrate humoral factors: cytokines as mediators of cell survival // Prog. Mol/ Subcell. Biol. - 2004.-Vol.34.-P.1-25.

87. Papa S., Zazzeroni F., Pham C.G., Bubici C., Franzoso G. Linking JNK signaling to NF- $\mathrm{KB}$ : a key to survival // J. Cell. Sci.-2004.-Vol.117, №Pt22.-P.51975208. 
88. Pennock J.L., Wipasa J., Gordge M.P., Meyer D.J. Interaction of macrophage-migration-inhibitory factor with haematin // Biochem. J.-1998.-Vol.331, Pt.3.-P.905-908.

89. Pestka S., Krause C.D., Sarkar D., Walter M.R., Shi Y., Fisher P.B. Interleukin-10 and related cytokines and receptors // Annu. Rev. Immunol.-2004.Vol.22.-P.929-979.

90. Petrenko O., Fingerle-Rowson G., Peng T., Mitchell R.A., Metz C.N. Macrophage migration inhibitory factor deficiency is associated with altered cell growth and reduced susceptibility to Ras-mediated transformation // J. Biol. Chem.-2003.-Vol.278, №13.P.11078-11085.

91. Petrovsky N., Bucala R. Macrophage migration inhibitory factor (MIF). A critical neurohumoral mediator // Ann. N. Y. Acad. Sci.-2000.-Vol.917.-P.665671.

92. Potolicchio I., Santambrogio L., Strominger J.L. Molecular interaction and enzymatic activity of macrophage migration inhibitory factor with immunorelevant peptides // J. Biol. Chem.-2003.-Vol.278, №33.P.30889-30895.

93. Pozzi L.M., W.Y. Weiser. Recombinant human macrophage migration inhibitory factor activates human monocyte derived macrophages to kill tumor targets // FASEB J.-1991.-Vol.5.-P.A4184.

94. Ren Y., Tsui H.T., Poon R.T., Ng I.O., Li Z., Chen Y., Jiang G., Lau C., Yu W.C., Bacher M., Fan S.T. Macrophage migration inhibitory factor: roles in regulation tumor cell migration and expression of angiogenic factors in hepatocellular carcinoma // Cancer-2003.Vol.107, №1.-P.22-29.

95. Rosengren E., Aman P., Thelin S., Hansson C., Ahlfors S., Bjork P., Jacobsson L., Rorsman H. The macrophage migration inhibitory factor MIF is a phenylpyruvate tautomerase // FEBS Lett.-1997.-Vol.417, №1.-P.85-88.

96. Rosengren E, Bucala R, Aman P, Jacobsson L, Odh G, Metz CN, Rorsman H. The immunoregulatory mediator macrophage migration inhibitory factor (MIF) catalyzes a tautomerization reaction // Mol. Med.-1996.-Vol.2, №1.-P.143-149.

97. Sakai M., Nishihira J., Hibiya Y., Koyama Y., Nishi S. Glutathione binding rat liver 13k protein is the homologue of the macrophage migration inhibitory factor // Biochem. Mol. Biol. Int.-1994.-Vol.33, №3.P.439-446.

98. Sampey A.V., Hall P.H., Mitchell R.A., Metz C.N., Morand E.F. Regulation of synoviocyte phospholipase A2 and cyclooxygenase 2 by macrophage migration inhibitory factor // Arthritis Rheum.-2001.Vol.44, №6.-P.1273-1280.

99. Santos L., Hall P., Metz C., Bucala R., Morand E.F. Role of macrophage migration inhibitory factor (MIF) in murine antigen-induced arthritis: interaction with glucocorticoids // Clin. Exp. Immunol.-2001.Vol.123, №2.-P.309-314.

100. Santos L.L., Lacey D., Yang Y., Leech M., Morand E.F. Activation of synovial cell p38 MAP kinase by macrophage migration inhibitory factor // J. Rheumatol.-2004.-Vol.31, №6.-P.1038-1043.

101. Satoskari A.R., Bozza M., Rodriguez Sosa M., Lin G., David J.R. Migration-inhibitory factor genedeficient mice are susceptible to cutaneous Leishmania major infection // Infect. Immun.-2001.-Vol.69, №2.P.906-911.

102. Senda T., Shimazu T., Matsuda S., Kawano G., Shimizu H., Nakamura K.T., Mitsui Y. Three-dimensional crystal structure of recombinant murine interferon-beta // EMBO J.-1992.-Vol.11, №9.-P.31933201.

103. Shen L., Hu J., Lu H., Wu M., Qin W., Wan D., Li Y.Y., Gu J. The apoptosis-associated protein BNIPL interacts with two cell proliferation-related proteins, MIF and GFER // FEBS Lett.-2003.-Vol.540, №1-3.P.86-90.

104. Sherry B., Yarlett N., Strupp A., Cerami A. Identification of cyclophilin as a proinflammatory secretory product of lipopolysaccharide-activated macrophages // PNAS-1992.-Vol.89, №8.-P.3511-3515.

105. Shimizu T., Nishihira J., Watanabe H., Abe R., Ishibashi T., Shimizu H. Cetirizine, an H1-receptor antagonist, suppresses the expression of macrophage migration inhibitory factor: its potential anti-inflammatory action // Clin. Exp. Allergy.-2004.-Vol.34, №1.P.103-109.

106. Shimizu T., Nishihira J., Watanabe H., Abe R., Honda A., Ishibashi T., Shimizu H. Macrophage migration inhibitory factor is induced by thrombin and factor Xa in endothelial cells // J. Biol. Chem.-2004.Vol.279, №14.-P.13729-13737.

107. Stavitsky A.B., Xianli J. In vitro and in vivo regulation by macrophage migration inhibitory factor (MIF) of expression of MHC-II, costimulatory, adhesion, receptor, and cytokine molecules. // Cell Immunol.-2002.-Vol.217, №1-2.-P.95-104

108. Sugimoto H, Suzuki M, Nakagawa A, Tanaka I, Nishihira J. Crystal structure of macrophage migration inhibitory factor from human lymphocyte at $2.1 \mathrm{~A}$ resolution // FEBS Lett.-1996.-Vol.389, №2.-P.145148.

109. Sugimoto H., Taniguchi M., Nakagawa A., Tanaka I., Suzuki M., Nishihira J. Crystal structure of human D-dopachrome tautomerase, a homologue of macrophage migration inhibitory factor, at $1.54 \mathrm{~A}$ resolution // Biochemistry-1999.-Vol.38? №11.-P.32683279 .

110. Sun B., Nishihira J., Suzuki M.,Fukushima N., Ishibashi T., Kondo M., Sato Y., Todo S. Induction of macrophage migration inhibitory factor by lysophosphatidic acid: relevance to tumor growth and angiogenesis // Int. J. Mol. Med.-2003.-Vol.12, №4.-P.633-641.

111. Suzuki H., Kanagawa H., Nishihira J. Evidence for the presence of macrophage migration inhibitory factor in murine reproductive organs and early embryos // Immunol. Lett.-1996.-Vol.51, №3.-P.141-147.

112. Swope M.D., Lolis E. Macrophage migration inhibitory factor: cytokine, hormone, or enzyme? // Rev. Physiol. Biochem. Pharmacol.-1999.-Vol.139.-P.1-32. 
113. Swope M., Sun H.W., Blake P.R., Lolis E. Direct link between cytokine activity and a catalytic site for macrophage migration inhibitory factor // EMBO J.-1998.-Vol.17, №13.-P.3534-3541.

114. Swope M.D., Sun H.W., Klockow B., Blake P., Lolis E. Macrophage migration inhibitory factor interactions with glutathione and S-hexylglutathione // J. Biol. Chem.-1998.-Vol.273,№24.-P.14877-14884.

115. Takahashi M., Nishihira J., Shimpo M., Mizue Y., Ueno S., Mano H., Kobayashi E., Ikeda U., Shimada K. Macrophage migration inhibitory factor as a redox-sensitive cytokine in cardiac myocytes // Cardiovasc. Res.-2001.-Vol.52, №3.-P.438-445.

116. Takase H., Sugita S., Rhee D.J., Imai Y., Taguchi C., Sugamoto Y., Tagawa Y., Nishihira J., Russell P., Mochizuki M. The presence of macrophage migration inhibitory factor in human trabecular meshwork and its upregulatory effects on the Thelper 1 cytokine // Invest. Ophthalmol. Vis. Sci.-2002.-Vol.43, №8.P.2691-2696.

117. Ueno M., Sugita T., Murakami T., Takata I. The novel anti-rheumatic drug TA-383 has a macrophage migration enhancing activity // Jpn. J. Pharmacol.1997.-Vol.74, №2.-P.221-224.

118. Vu T.K., Hung D.T., Wheaton V.I., Coughlin S.R. Molecular cloning of a functional thrombin receptor reveals a novel proteolytic mechanism of receptor activation // Cell-1991.Vol.64, №6.-P.1057-1068.

119. Vu T.K., Wheaton V.I., Hung D.T., Charo I., Coughlin S.R. Domains specifying thrombin-receptor interaction // Nature-1991.-Vol.353, №6345.-P.674677.

120. Wadgaonkar R., Dudek S., Zaiman A., LinzMcGillem L., Verin A., Nurmukhambetova S., Romer L., Garcia J. Intracellular interaction of myosin light chain kinase with macrophage migration inhibition factor (MIF) in endothelium// J. Cell. Biochem.- 2005.Vol. 95, № 4. - P. 849-858.

121. Waeber G., Calandra T., Bonny C., Bucala R. A role for the endocrine and pro-inflammatory mediator MIF in the control of insulin secretion during stress // Diabetes Metab. Res. Rev.-1999.-Vol.15, №1.-P.47-54.

122. Waeber G., Calandra T., Roduit R., Haefliger J.A., Bonny C., Thompson N., Thorens B., Temler E., Meinhardt A., Bacher M., Metz C.N., Nicod P., Bucala $\mathrm{R}$. Insulin secretion is regulated by the glucose-dependent production of islet beta cell macrophage migration inhibitory factor // PNAS-1997.-Vol.94, №9.P.4782-4787.

123. Watanabe H., Shimizu T., Nishihira J., Abe R., Nakayama T., Taniguchi M., Sabe H., Ishibashi T.,
Shimizu H. Ultraviolet A-induced production of matrix metalloproteinase-1 is mediated by macrophage migration inhibitory factor (MIF) in human dermal fibroblasts // J. Biol. Chem.-2004.-Vol.279, №3.-P.16761683.

124. Watarai H., Nozawa R., Tokunaga A., Yuyama N., Tomas M., Hinohara A., Ishizaka K., Ishii Y. Posttranslational modification of the glycosylation inhibiting factor (GIF)gene product generates bioactive GIF // PNAS-2000.-Vol.97, №24.-P.13251-13256.

125. Weiser W.Y., Temple P.A., Witek-Giannotti J.S., Remold H.G., Clark S.C., David J.R. Molecular cloning of a cDNA encoding a human macrophage migration inhibitory factor // PNAS - 1989.-Vol.86.P.7522-7526.

126. Willson D.F. Cytokine pharmasciences licenses anti-MIF technology to Baxter Healthcare Corporation // Cytokine PharmaSciences, Inc.-2003.

127. Wistow G.J., Shaughnessy M.P., Lee D.C., Hodin J., Zelenka P.S. A macrophage migration inhibitory factor is expressed in the differentiating cells of the eye lens // PNAS-1993.-Vol.90, №4.-P.1272-1275.

128. Wu J., Cunha F.Q., Liew F.Y., Weiser W.Y. IL-10 inhibits the synthesis of migration inhibitory factor and migration inhibitory factor-mediated macrophage activation // J. Immunol.-1993.-Vol.151, №8.P.4325-4332.

129. Wymann D., Bluggel M., Kalbacher H., Blesken T., Akdis C.A., Meyer H.E., Blaser K. Human B cells secrete migration inhibition factor (MIF) and present a naturally processed MIF peptide on HLA-DRB1* *0405 by a FXXL motif // Immunology.-1999.-Vol.96, №1.-P.1-9.

130. Yasuda Y., Kasuya K., Nishihira J., Sasaki Y., Tsuchida A., Aoki T., Koyanagi Y. Induction of cell arrest by transfection of macrophage migration inhibitory factor antisense plasmid // Int. J. Mol. Med.-2002.Vol.10, №4.-P.463-467.

131. Zwadlo G., Bruggen J., Gerhards G, Schlegel R., Sorg C. Two calcium-binding proteins associated with specific stages of myeloid cell differentiation are expressed by subsets of macrophages in inflammatory tissues.// Cli. Exp. Immunol.-1988.-V.72.-No3.-P.510515.

132. А.С.Симбирцев. Цитокины - классификация и биологические функции // Цитокины и воспаление - 2004.- Т.3, №2.-С.16-22.

133. А.П. Суслов, О.Ю. Третьяков, М.В. Коноплева. Структурные и функциональные особенности MIF // Медицинская иммунология - 2004.-T.6, №35.-C.193-200.

поступила в редакцию 01.11.2005 принята к печати 15.11.2005 